\title{
Impact of Spatial Misallocation of Electric Power Resources on Economic Efficiency and Carbon Emissions in China
}

\section{Delu Wang ( $\sim$ dlwang@cumt.edu.cn )}

China University of Mining and Technology

\section{Suqing Zhang}

China University of Mining and Technology

\section{Yadong Wang}

China University of Mining and Technology

Jinqi Mao

China University of Mining and Technology

\section{Research Article}

Keywords: Electric power resources, Spatial misallocation, Spatial differentiation, Temporal differentiation, Economic efficiency, Carbon emissions

Posted Date: November 2nd, 2021

DOl: https://doi.org/10.21203/rs.3.rs-961970/v1

License: (c) (i) This work is licensed under a Creative Commons Attribution 4.0 International License. Read Full License

Version of Record: A version of this preprint was published at Environmental Science and Pollution Research on March 22nd, 2022. See the published version at https://doi.org/10.1007/s11356-022-191006. 


\title{
1 Impact of Spatial Misallocation of Electric Power Resources on Economic 2 Efficiency and Carbon Emissions in China
}

3 Delu Wang*, Suqing Zhang, Yadong Wang, Jinqi Mao

4 School of Management, China University of Mining and Technology, Xuzhou, Jiangsu 221116, P. R. China

\begin{abstract}
The relationship between resource misallocation and productivity has become a hot topic in recent years, but few studies examined the impact of spatial misallocation of electric power resources (SMEPRs) ${ }^{1}$ on economic efficiency and carbon emissions. Here, we constructed a calculation model of SMEPRs that can measure both the misallocation degree and direction and uncovered the spatiotemporal evolvement mechanism of SMEPRs. On this basis, we explored the impact of SMEPRs on regional economic efficiency and carbon emissions using panel data from 29 provinces in China from 1988-2017. The results demonstrate that the high level of SMEPRs in China shows complex spatiotemporal characteristics and significantly affects the regional economic efficiency and carbon emissions. Specifically speaking: first, SMEPRs presents the characteristics of the coexistence of excessive and insufficient allocation among provinces and regions, the increasing extent of misallocation in the eastern and western regions, and the gradual decline in the central region; second, SMEPRs has a strong negative effect on the regional economic efficiency and carbon emissions by affecting regional industrial structures, which indicates that SMEPRs is an important factor restricting the high-quality development of regional economies. The research observations offer fresh insights to upgrading the high-quality and green development of China's power sector and promoting regional economic transformation and ecological sustainability.
\end{abstract}

Keywords: Electric power resources; Spatial misallocation; Spatial differentiation; Temporal differentiation; Economic efficiency; Carbon emissions

\footnotetext{
* Corresponding author.
}

E-mail address: dlwang@cumt.edu.cn (D.L. Wang)

1 Abbreviations

SMEPRs: spatial misallocation of electric power resources 
Jel classification: Q41; Q48

\section{Introduction}

Since the reform and opening-up policies were implemented, China has experienced 40 years of rapid growth, and its economy has become the second-largest in the world. China accounts for more than $30 \%$ of global economic growth and has increasingly become a driving force for growth (Freeman, 2019). However, the presence of a high level of economic growth does not necessarily mean that high-quality economic development is taking place. At present, problems such as extensive economic growth, unbalanced regional development, and serious environmental pollution still plague China's economic and social development, which largely constrains the sustainability of economic growth (Xu and Tan, 2020; Zhou et al., 2020; Wu et al., 2018). As such, the report of the 19th National Congress of the Communist Party of China put forward the concept of high-quality development. And this has become the foundation of China's economic and social development in the new era. This also means that China has shifted from pursuing the "high-speed" economic growth of the past to focusing on "high-quality" economic development. Both the classic theories of development economics and the latest research results show that the effectiveness of resource allocation is a key factor affecting the likelihood of realizing high-quality development (Kong et al., 2021). The misallocation of resources across regions, industries, and various sectors leads to inefficient resource allocation and affects the short-term total output. It also affects the long-term output combination of the economy and seriously challenges the sustainability of economic growth (Hsieh and Klenow, 2009). As a country in transition, China has been confronted with the serious problem of spatial misallocation of resources. And this is due to the existence of factors such as regional market segmentation, government intervention, and enterprise ownership differences. In particular, electric power resources are indispensable production factors to satisfy the development of all sectors of the national economy. Since the power system reform in 2015, China has made some achievements in the construction of the power resource market. For example, the power supply structure has been improved, and the power production capacity has been controlled. Nevertheless, the market-oriented pricing and allocation mechanism of electric power resources have not been realized. Meanwhile, thermal power generation is still the main mode of power production in China, which is the main cause of air pollution and carbon dioxide emissions (Wang et al., 2020). Moreover, in the critical period of China's high-quality economic development and the transformation of old and new kinetic energy, the allocation of electric power resources is deserved to be discussed. Moreover, this has important theoretical and practical significance for improving the spatial allocation efficiency of electric power resources and realizing the coordinated development of the regional economy (Zheng et al., 2020).

In recent years, given the adverse effects of spatial resource misallocation, scholars have carried out many fruitful discussions on the ideal method for measuring it (Hsieh and Klenow, 2009; Chen and Hu, 2011), its formation mechanisms (Haley et al., 2013; Wu et al., 2018), and its economic effects (Brandt, 2012; Hao et al., 2020). However, some defects are mainly reflected in the following three issues: First, In terms of research objects, most studies focus on essential production factors such as capital, land, and labor. There are also some studies discussing the problem of energy misallocation (Chu et al., 2019; Yang et al., 2018; Choi B, 2020), whereas there is still a lack of research on 
spatial misallocation of electric power resources (SMEPRs). There is still a lack of research on further refining energy resources into power resources and addressing their spatial misallocation in a targeted manner. Second, on the impact of spatial resource misallocation, the existing literature mainly focuses on the impact on economic efficiency. And there is also a small amount of literature that focuses on the impact of resource misallocation on the environment (Wang et al., 2020; Hao et al., 2020). However, kinds of literature focus on the environmental effects of SMEPRs. Finally, most of the existing literature investigates the direct impact of resource misallocation on economic efficiency (Hao et al., 2020), ignoring the internal transmission mechanism that causes this impact. This is, undoubtedly, not conducive to the development of resource misallocation theory or the targeted formulation of policies by the relevant government departments.

Because of the limitations of the existing literature, this paper uses provincial panel data to measure and analyze the SMEPRs in each province in China. On this basis, the transmission mechanism of the impact of SMEPRs on regional economic efficiency and carbon emission is investigated. The main contributions of this study are as follows: First, the research perspective on the problem of resource spatial resource misallocation has been expanded. Based on the characteristics of the geographical and price segmentation of China's electric power market, energy factors are further refined into electric power factors. The degree, direction and temporal and spatiotemporal patterns of power resource mismatch in 29 provinces of China are quantitatively revealed. Second, the research content of spatial resource misallocation has been enriched. This paper not only focuses on the impact of SMEPRs on economic efficiency but also examines its impact on regional environmental quality from the perspective of carbon emissions. This provides a new theoretical explanation for understanding the spatiotemporal heterogeneity of regional economic quality in China. Third, the research chain of spatial resource misallocation has been improved. This paper proposes a theoretical analysis framework of " spatial misallocation of resources $\rightarrow$ regional industrial structure $\rightarrow$ economic efficiency and carbon emissions ". The empirical study reveals how SMEPRs affect economic efficiency and carbon emission intensity through the industrial structure. This provides a valuable reference for promoting regional economic upgrading and achieving high-quality development.

The remainder of this paper is organized as follows: Section 2 is a historical study of resource misallocation. In Section 3, a theoretical analysis is presented. In Section 4, the research design of the mediating effect model and variable descriptions are presented. The results are discussed in Section 5, and Section 6 includes conclusions, policy implications, and outlook.

\section{Literature review}

\subsection{The connotations and causes of resource misallocation}

Resource misallocation is related to the effective allocation of resources. The "effective allocation of resources" refers to the state of optimal allocation in which resources can flow ultimately freely, achieve Pareto optimization, and maximize the total output. "Resource misallocation" refers to the existence of external factors that cause obstacles to the flow of resources, which causes the marginal output of resources to be unequal, that is, to deviate from the optimal Pareto state (Chen and $\mathrm{Hu}, 2011)$. Resource misallocation shows remarkable universality and diversity. It manifests in various forms, such as capital misallocation, labour misallocation, land misallocation, technology misallocation, and 
financial misallocation (Hsieh and Klenow, 2009; Huang and Du, 2017; Hu et al., 2020; Yang and Lee, 2021). In recent years, air pollution has become increasingly severe, and the pressure of carbon emission reduction has increased significantly. Because of this, the research on energy misallocation has gradually attracted the attention of scholars. For example, Chu et al.(2019) showed an inverted U-shaped non-linear relationship between energy misallocation and carbon emission efficiency. The existing literature shows that the causes of resource misallocation fall into two categories. One is related to the incompleteness of the market itself, including financial friction (Karabarbounis and Macnamara, 2021; Wu, 2018), financing constraints (Banerjee and Moll, 2010), and a dysfunctional banking system. The other is related to excessive government intervention, such as financial subsidies (Haley et al., 2013; Sun et al., 2020), ownership discrimination (Huang and Du, 2017), and administrative monopolies (Li et al., 2012). In addition, local governments that prioritize maximizing local economic growth while neglecting overall efficiency also make resource misallocation more serious. In general, scholars have formed a relatively unified understanding of the connotations and causes of resource misallocation. And they have achieved many positive and fruitful results, which provide the necessary theoretical basis for correcting resource misallocation. Nevertheless, the existing research is mainly focused on the basic production factors. Furthermore, research on the misallocation of energy, especially the factors involved in energy subdivision, is still scarce. Energy-related factors, especially electric power, are indispensable production factors that drive economic development. The government strictly controls the regional distribution of the power supply and grid, so it is necessary to carry out in-depth research on SMEPRs.

\subsection{Measurement method of resource misallocation}

In research on measuring resource misallocation, the work of Hsieh and Klenow (2009) is highly representative. Before their work, the measurement of resource misallocation was not accurate enough, and there was a lack of systematic measurement methods. Thus, most of the current literature on resource misallocation originates from Hsieh and Klenow's research ideas (2009). They constructed a monopoly competition model for heterogeneous firms based on the Cobb-Douglas production function with constant returns to scale (short for HK model). Using micro firm survey data, they quantified the model and found that resource misallocation severely lowered TFP. There are two main measurement methods based on the HK model. One is to measure the loss of TFP, that is, the difference between the actual TFP and the optimal Pareto TFP. For example, Brandt et al. (2013) broke through the restriction of a single sector and used the aggregate data of China's manufacturing industry to deconstruct the TFP growth rate. They then measured the TFP losses in China's non-agricultural economy caused by resource misallocation at the macro level. The other is to measure the distortion of the factor input by assuming that the distortion is reflected in $\mathrm{f}$ a price tax. For example, Oberfield (2013) defined the distortions of capital, labour, and intermediate inputs at the firm level. And he measured the distortions of factor inputs at the industry and country levels using a similar method. Chen and $\mathrm{Hu}$ (2011) combined the discussion on resource misallocation and efficiency loss with the traditional Syrquin framework. And they conducted an empirical study on the extent of resource misallocation and its influence. Unlike in the HK model, they quantitatively discussed the changes in the misallocation of specific industries and specific factors and their impact on TFP and output changes. Overall, the above two methods can be used to measure the extent of resource misallocation accurately. The difference is that the former focuses on the results of resource misallocation, namely TFP loss, while the 
latter focuses on its potential causes. Thus, the latter is more conducive to achieving a deeper understanding of the formation mechanisms of specific factors of production distortion.

\section{3}

\subsection{The impact of resource misallocation}

In the current research on resource misallocation influence, the impact and extent on economic growth, especially TFP, is the topic most discussed by scholars. Moreover, it is mainly discussed from the enterprise, industry, and regional levels. At the firm-wide level, Syrquin (1984) paid attention to the relationship between resource allocation efficiency and TFP. By promoting Solow's growth accounting framework, Syrquin deconstructed productivity growth into the TFP of each industry and the allocation effect among various industries. He found that implementing resource reallocation across industries can significantly improve the productivity of the entire economy. The most groundbreaking study is Hsieh and Klenow (2009), who estimated resource misallocation in China and India, respectively. They discovered that correcting resource misallocation increased the TFP of China and India by 30-50\% and 40-60\%, respectively. Many subsequent studies on resource misallocation have adopted the research ideas of Hsieh and Klenow. At the industry-wide and regional level, Aoki (2012) discussed resource misallocation from the industry's perspective. And he found that $9 \%$ of the difference in aggregate productivity between Japan and the US was caused by resource misallocation. Overall, research on the impact of resource misallocation has been very rich but with some limitations. On the one hand, these studies confirm the effect of improving resource allocation on economic efficiency. But they ignore the indirect impact of resource misallocation on economic efficiency and cannot describe the internal transmission mechanism between the two. On the other hand, most of the existing literature is focused on the impact of resource misallocation on economic efficiency. It neglects its impact on issues related to environmental quality, especially carbon emissions.

\section{Theoretical analysis}

\subsection{Calculation model for SMEPRs}

Given that this study is focused on SMEPRs, directly measuring the distortion of factor input helps analyze the spatiotemporal heterogeneity of SMEPRs. Accordingly, based on the HK model, we will introduce a discussion of factor misallocation into traditional growth accounting and then construct a model for calculating SMEPRs.

\subsubsection{Production problems in the Province $N$}

We first considered the production problem of the Province $N$. This paper focuses on the misallocation of electric power resources among provinces, so we assumed that the elasticity of factors is heterogeneous among various provinces. Based on the Cobb-Douglas production function, it was assumed that each province included three factors of production: capital $(K)$, labour ( $L$ ), and electric power resources $(E)$. Similar to the HK model, we supposed that the factor prices faced by each province were distorted. And the distortion was supposed to be reflected in the form of price taxes. Specifically, the prices of capital, labour, and electric power resources faced by province $i$ in period $t$ would be $\left(1+\tau_{K i t}\right) P_{K_{i t}},\left(1+\tau_{L i t}\right) P_{L_{t t}}$, and $\left(1+\tau_{E i t}\right) P_{E_{i t}}$ respectively, where $P_{K_{i t}}, P_{L_{i t}}$, and $P_{E_{i t}}$ would be the price levels of the three productive factors under competitive conditions. And $\tau_{\text {Kit }}, \tau_{\text {Lit }}$, and $\tau_{\text {Eit }}$ would refer to the distorted "taxes" of capital, labour, and electric power resources in period $t$ in Province $i$, respectively. 
Suppose that the production function in period $t$ in Province $i$ is the following:

$$
Y_{\mathrm{it}}=A_{1} K_{i t}^{\beta_{\mathrm{ki}}} L_{i t}^{\beta_{\mathrm{Li}}} E_{i t}^{\beta_{E \mathrm{i}}}
$$

where $Y_{i t}, K_{i t}, L_{t t}$, and $E_{t t}$ are the output, capital input, labour input, and electric power input in period $t$ in Province $i$, respectively, and $\beta_{K i}, \beta_{L i}$, and $\beta_{E i}$ represent the output elasticity of capital, labour, and electric power in Province $i$, respectively. Let us assume that $\beta_{K i}+\beta_{L i}+\beta_{E i}=1$, or the return to scale is constant. To maximize the benefits:

$$
\max _{K_{i t}, L_{t}, E_{i t}}\left\{P_{i t} Y_{i t}-\left(1+\tau_{K i t}\right) P_{K_{i t}} K_{i t}-\left(1+\tau_{L i t}\right) P_{L_{i t}} L_{t t}-\left(1+\tau_{E i t}\right) P_{E_{i t}} E_{i t}\right\}
$$

where $P_{i t}$ is the product price in period $t$ and Province $i .^{2}$ The first-order condition of this optimization problem is the following:

$$
\begin{aligned}
& \beta_{L i} P_{i t} A_{i} K_{i t}^{\beta_{K i}} L_{i t}^{\beta_{L i}-1} E_{i t}^{\beta_{E i}}=\left(1+\tau_{L i t}\right) P_{L_{i t}} \\
& \beta_{K i} P_{i t} A_{i} K_{i t}^{\beta_{K i}-1} L_{i t}^{\beta_{L i}} E_{i t}^{\beta_{E i}}=\left(1+\tau_{K i t}\right) P_{K_{i t}} \\
& \beta_{E i} P_{i t} A_{i} K_{i t}^{\beta_{K i}} L_{i t}^{\beta_{L i}} E_{i t}^{\beta_{E i}-1}=\left(1+\tau_{E i t}\right) P_{E_{i t}}
\end{aligned}
$$

\subsubsection{Aggregate production functions and resource constraints}

The total output $Y_{t}$ (the final product of the society is the value of the economy, and the price is 1) of the whole economy during period $t$ is determined by the output of each province:

$$
Y_{t}=F\left(Y_{1 t}, \ldots, Y_{N t}\right)
$$

where $F(\cdot)$ is assumed to be constant returns to scale, therefore,

$$
\partial Y_{t} / \partial Y_{i t}=P_{i t}
$$

According to Euler's theorem:

$$
Y_{t}=\sum_{i=1}^{N} P_{i t} Y_{i t}
$$

This implies that, from the perspective of output value, the output value of the whole economy in period $t$ is equal to the total output value of each province. When the total amount of production factors in period $t$ is given exogenously, the following resource constraints exist:

$$
\sum_{i=1}^{N} K_{i t}=K_{t}, \quad \sum_{i=1}^{N} L_{i t}=L_{t}, \quad \sum_{i=1}^{N} E_{i t}=E_{t}
$$

\subsubsection{Competitive equilibrium}

Given the above setting, we can define competitive equilibrium with distortions when the productivity levels, distorted "taxes," and the total amount of factors in the economy in period $t$ are all given. Then, the distorted competitive equilibrium $\left\{K_{i t}, L_{i t}, E_{i t} ; P_{i t}, P_{K_{i t}}, P_{L_{i t}}, P_{E_{i t}} ; F\right\}$ satisfies the optimal first-order conditions for $N$ provinces,

\footnotetext{
${ }^{2}$ Given that goods in China are now much more market-oriented than factors of production, it is assumed that there is no price distortion in the product market.
} 
(3)-(5); the constant returns to scale of the aggregate production function, (6) and (7); and the resource constraints, (9). The value of $E_{i t}$ in competitive equilibrium with distortion is represented as follows: ${ }^{3}$

$$
E_{i t}=\frac{\frac{P_{i t} \beta_{E i} Y_{i t}}{\left(1+\tau_{E i t}\right) P_{E i t}}}{\sum_{j} \frac{P_{j t} \beta_{E j} Y_{j t}}{\left(1+\tau_{E j t}\right) P_{E j t}}} E_{t}
$$

For further analysis, we defined two types of "distortion coefficients," which are as follows:

The absolute distortion coefficient of electric power resources in period $t$ in Province $i$ is defined as follows:

$$
\gamma_{E_{i t}}=\frac{1}{1+\tau_{\text {Eit }}}
$$

In the equilibrium of competition, the output value of Province $i$ in the whole economy during period $t$ is $s_{i t}=Y_{i t} / Y_{t}$. The contribution value of electric power resources weighted by output is $\beta_{E}=\sum_{i}^{N} s_{i t}\left|\beta_{E i}\right| \cdot\left|\beta_{E i}\right|$ is the absolute value of the output elasticity of electric power resources in Province $i$. Then, the relative distortion coefficient of the electric power resource price can be defined as follows:

$$
\hat{\gamma}_{E i t}=\frac{\gamma_{E i t}}{\sum_{j=1}^{N}\left(\frac{s_{j t}\left|\beta_{E j}\right|}{\beta_{E}}\right) \gamma_{E i t}}
$$

where $\gamma_{\text {Eit }}$ is the absolute distortion coefficient of electric power resources in period $t$ in Province $i$.

When determining the allocation of factors between provinces, we must note that what matters is the "relative," not the "absolute" distortion of factor prices. This can be observed in optimal conditions. If the absolute distortion of electric power resources in all provinces changes simultaneously, it increases the price of electric power resources by the same proportion. In this case, the relative price of electric power resources in each region remains unchanged, and the allocation of electric power resources among provinces also remains unchanged. Suppose there is no factor-distortion "tax" on the whole economy. In that case, we can assume that the relative distortion of the price of electric power resources in all provinces is 1 , meaning no resource misallocation.

In the face of actual data, it was impossible to carry out actual measurements due to the lack of important information about the actual price of electric power resources. Therefore, the relative distortion coefficient of electric power resources, which can be obtained from equations (10) and (12), was adopted in this study:

$$
E_{i t}=\frac{s_{i t}\left|\beta_{E i}\right|}{\beta_{E}} \gamma_{E i t} E_{t}
$$

Thus, the relative distortion coefficient of electric power resources in period $t$ in Province $i$ can be expressed as follows:

$$
\hat{\gamma}_{E i t}=\left(\frac{E_{i t}}{E_{t}}\right) /\left(\frac{s_{i t}\left|\beta_{E i}\right|}{\beta_{E t}}\right)
$$

The numerator $\frac{E_{i t}}{E_{t}}$ is the actual proportion of the power resource input in period $t$ in Province $i$ to the total

${ }^{3}$ Since we focused on SMEPRs, only the values related to power resources are shown in this paper. 
power resource input in period $t$. The denominator $\frac{s_{i t}\left|\beta_{E i}\right|}{\beta_{E t}}$ measures the theoretical proportion of the total power resources that should be consumed when effectively allocated during period $t$. The ratio of the two reflects the level of SMEPRs in period $t$ in Province $i$. If $\hat{\gamma}_{\text {Eit }}$ is greater than and severely deviates from 1, it indicates that, compared to the overall economy, the power resource cost in period $t$ in Province $i$ is low. And this will lead to the overuse of electric power resources. Conversely, if $\hat{\gamma}_{\text {Eit }}$ is under 1 and close to 0 , it means that, compared to the overall economy, the power resource cost in period $t$ in Province $i$ is high. As a result, the actual allocation of electric power resources in such a province is bound to be lower than the theoretical level. And the allocation of electric power resources is insufficient. Through equation (14), we can express the invisible factor price distortion coefficient visibly and establish a connection between factor cost distortion and SMEPRs.

\subsection{Analysis of the transmission mechanism of SMEPRs}

In the face of the infinite growth of human needs, resources are always limited within time and space. In the context of the absolute growth of human needs, the relative insufficiency of resources results in scarcity. A scarcity of resources indicates that the limited resources must be allocated to various fields to achieve the best use. If the limited resources cannot be allocated reasonably and effectively, a situation of low efficiency in economic activities in the medium and long term arises, which hinders the long-term sustainable development of the economy (Hsieh and Klenow, 2009; Chu et al., 2016). In the specific context of electric power resources, the unreasonable allocation leads to distortions in the electricity market. This may result in the underestimation of electric power prices in areas with abundant power resources. Further, this makes backward production capacity remain profitable and induces regional energy-intensive enterprises to form a lock-in effect of extensive growth. And this weakens the willingness and motivation of enterprises to engage in further technological innovation, which, in turn, restricts the improvement of industrial productivity and aggravates regional environmental pollution. More importantly, as the most significant contributor to carbon emissions, its excessive accumulation inevitably directly leads to the growth of regional carbon emissions (Teng et al., 2017).

The former industrial structure theory is often based on the assumption of complete competition in the factor market. The various industrial sectors have the same factor prices, but the resource allocation within each sector is also completely effective. This hypothesis is inconsistent with the actual situation in China, which is in a transitional stage. The unbalanced development of China's three industries and changes in the industrial structure exist alongside resource misallocation. In the specific context of electric power resources, the regional allocation policy of electric power resources changes the comparative advantages of each region. For the sake of long-term sustainable development, energy-intensive firms are more inclined to choose production in areas where the required resources are relatively abundant, and the factor costs are relatively low. The richer the regional power resources, the stronger the intention of electric power consuming enterprises to expand. This is also more attractive to energy-intensive firms, which leads to the excessive accumulation of energy-intensive firms in areas with abundant power resources. In response to electric power shortages, areas with few electric power resources usually prioritize ensuring residential power consumption, 
while "power rationing" is adopted for industrial firms. And thus force energy-intensive firms to move away. In doing so, such firms become over-aggregated in areas with abundant power resources. In this way, the proportion of industries, especially heavy chemical ones, in the regional economy increases, and the development space of tertiary industries becomes squeezed. A large volume of evidence shows that the share accounted of secondary industries plays a significant role in increasing carbon emissions in various regions (Elliott and Shanshan, 2008). Meanwhile, due to resource dependence, the SMEPRs will inhibit the innovation motivation of enterprises and hinder the upgrading of the industrial structure. And the dependency would further result in inhibiting the promotion of regional economic efficiency and carbon reduction processes. In summary, we propose the following theoretical analysis framework: "spatial misallocation of electric power resources $\rightarrow$ regional industrial structure $\rightarrow$ economic efficiency and carbon emissions," as shown in Figure 1.

\section{Insert Fig. 1 here.}

\section{Research Design}

\subsection{Mediation model}

In the empirical analysis, when examining the influence of the independent variable $X$ on the dependent variable $Y$, if the independent variable $X$ affects the dependent variable $Y$ through the variable $M$, then $M$ is called the mediating variable, and the indirect influence of $X$ through $M$ on $Y$ is the mediating effect. $c$ is $X$ versus $Y$, the total effect of $a b$ is the mediation effect transmitted through the mediator variable, and $c^{\prime}$ is the direct effect. According to the previous analysis, in the relationship between the level of SMEPRs and regional economic efficiency and carbon emissions, industrial structure $(I S)$ is the mediating variable, the level of SMEPRs $(E M)$ is the independent variable, and economic efficiency $(E C)$ and carbon emissions $(C O 2)$ are the dependent variables. The regression model with $E C$ as the dependent variable is shown in equation (15), and the regression model with $\mathrm{CO} 2$ as the dependent variable is shown in equation (16).

$$
\begin{aligned}
& \left\{\begin{array}{l}
E C_{i t}=\alpha_{4}+c_{2} E M_{i t}+\text { control }_{i t} \delta_{4}+\mu_{i 4}+v_{t 4}+\varepsilon_{i t 4} \\
I S_{i t}=\alpha_{5}+a_{2} E M_{i t}+\text { control }_{i t} \delta_{5}+\mu_{i 5}+v_{t 5}+\varepsilon_{i t 5} \\
E C_{i t}=\alpha_{6}+c_{2}^{\prime} E M_{i t}+b_{2} I S_{i t}+\text { control }_{i t} \delta_{6}+\mu_{i 6}+v_{t 6}+\varepsilon_{i t 6}
\end{array}\right. \\
& \left\{\begin{array}{l}
C O 2_{i t}=\alpha_{1}+c_{1} E M_{i t}+\text { control }_{i t} \delta_{1}+\mu_{i 1}+v_{t 1}+\varepsilon_{i t 1} \\
I S_{i t}=\alpha_{2}+a_{1} E M_{i t}+\text { control }_{i t} \delta_{2}+\mu_{i 2}+v_{t 2}+\varepsilon_{i t 2} \\
C O 2_{i t}=\alpha_{3}+c_{1}^{\prime} E M_{i t}+b_{1} I S_{i t}+\text { control }_{i t} \delta_{3}+\mu_{i 3}+v_{t 3}+\varepsilon_{i t 3}
\end{array}\right.
\end{aligned}
$$

where $i$ and $t$ represent the province and year, respectively, Control is the control variable, $\mu$ is the individual effect, $v$ is the time effect, and $\varepsilon$ is the random disturbance term.

\subsection{Variable selection and data description}

\subsubsection{Core explanatory variable}

The core independent variable is the level of SMEPRs, which can be calculated using the SMEPRs calculation model proposed in this paper. Before calculation, it is necessary to calibrate the relevant parameters involved in the calculation model for SMEPRs. The details are as follows: Regarding Hsieh and Klenow (2009), we set the cost of capital $P_{K_{i t}}$ to $=10 \%$ and set $\sigma$ as 3 . The value of $P_{K_{i t}}$ affects only the average capital distortion. In addition to 
setting $P_{K_{i t}}$ and $\sigma$, we needed to know the elasticity of the three production factors to calculate the misallocation

index. Because of the heterogeneity of the provinces, the variable coefficient fixed-effect model was used to estimate the elastic coefficient of the production factors in equation (1).

The remaining includes the total regional output value $Y_{i t}$, labour remuneration $P_{K_{i t}} K_{i t}$, capital remuneration $P_{L_{t}} L_{i t}$, and electric power resource input $P_{E_{i t}} E_{i t}$. Referring to Liu and Wu (2019), the GDP of each province measured the total regional output value $Y_{i t}$. Labour remuneration $P_{L_{t}} L_{t}$ was measured by the actual number of employees at the end of the year in each province. The input of electric power resources $P_{E_{i t}} E_{i t}$ was measured by the electricity consumption of each province. The capital stock $K_{i t}$ was calculated using the perpetual inventory method. And the calculation formula was $K_{i t}=I_{i t} / P_{i t}+(1-\theta) K_{i t-1}$ where $K_{i t}, I_{i t}$, and $P_{i t}$ represented the fixed capital stock, nominal total fixed capital formation, and fixed asset investment price index in period $t$ in Province $i$, respectively. In the selection of depreciation rate, we refer to Jun et al. (2004) and set the depreciation rate $\theta$ to $9 \%$. The investment index of the current year is the total fixed capital formation, and it is considered a reasonable index. For the capital stock in the base period, the capital stock in 1988 calculated by Jun et al. (2004) was directly adopted. The price index of fixed-asset investment was published in the China Statistical Yearbook in 1993, and there are only time-series data available after 1991. To this end, referring to Jun et al. (2004), the provincial investment-implied deflator replaced the price index of investment goods before 1993. And the data after 1993 were directly derived from the price index of fixed-asset investment published in the China Statistical Yearbook. The data of the above-related indicators mainly came from the 1988-2017 China Statistical Yearbook, China Labour Statistics Yearbook, China Electric Power Yearbook, China GDP Accounting Historical Data 1952-1995, and the statistical yearbooks of the various provinces. The missing data were supplemented by interpolation, and the price variables were deflated to the base period level in 1988.

According to the calculation model of SMEPRs, the closer EM is to 1, the smaller the degree of the SMEPRs will be; the more it deviates from 1, the greater the degree of SMEPRs will be. Thus, EM is a moderate index. To facilitate the analysis, the normalization was processed using formula (17):

$$
E M^{\prime}=\frac{E M-1}{E M_{\max }-E M_{\min }}
$$

\subsubsection{Intermediary variable}

The intermediary variable was the provincial industrial structure. Concerning Liu et al. (2020) and considering that secondary industries contribute the most to the total electricity consumption of society, ${ }^{4}$ we used the proportion of the added value of secondary industries to the GDP to measure the industrial structure. The relevant data were obtained from the China Statistical Yearbook and the provincial statistical yearbooks.

\footnotetext{
${ }_{4}$ According to the statistics in the China Statistical Yearbook.
} 


\subsubsection{Explained variables}

\section{(1) Economic efficiency}

TFP comprehensively reflects the overall efficiency of converting input into output over a specific period and can measure provincial economic efficiency well (Feng et al., 2018). For this reason, we used TFP to measure regional economic efficiency. Moreover, the specific calculation method was as follows: The Manquist Index method based on data envelopment analysis (DEA) was used to calculate TFP. Specifically, capital stock, labour input, and electric power consumption were selected as input indicators, and the GDP of each province was selected as the output indicator. The data sources for the relevant indicators were the same as those in Section 4.2.1.

(2) Carbon emissions

The existing literature has generally used the amount of carbon emissions and carbon emissions intensity (i.e., the amount of carbon emissions per unit of GDP) to characterize carbon emissions. There is currently no direct official data on carbon emissions, which are generally calculated based on statistical data from various provinces. There are three main calculation methods. The first is to use the consumption of coal, oil, natural gas, and other primary energy sources to multiply the corresponding carbon emissions coefficient. The second is to multiply the main energy consumption of each province by the corresponding carbon emissions coefficient and add the values up to obtain the total carbon emissions of the provinces. The third is to calculate the carbon emissions of cities and towns, transportation, and based on the final energy consumption reported on China's energy balance sheet. Carbon emission coefficients are mostly based on the data in the Guidelines for National Greenhouse Gas Inventories issued by the IPCC. Some scholars also use data provided by the Energy Research Institute of the National Development and Reform Commission. The main source of carbon emissions is the burning of fossil fuels. However, China's fossil fuel reserves are abundant and diverse, making a detailed classification of emissions sources difficult. Considering that carbon emissions data cannot be directly obtained, we drew on the practices of the National Climate Change Coordination Group Office, the Energy Research Institute of the National Development and Reform Commission, and the work of related scholars (Chen et al., 2021; Zhang et al., 2021). We extracted eight major energy sources: coal, coke, crude oil, gasoline, kerosene, diesel, fuel oil, and natural gas, to calculate carbon emissions. The carbon emissions calculation formula is as follows:

$$
C O_{2}=\sum_{j=1}^{8} Q_{i j} \times C_{j}
$$

where $Q_{i j}$ is the consumption of energy $j$ in province $i$ measured by standard coal. And it is calculated as the product of the consumption of the energy source and the standard coal conversion coefficient. The energy consumption and conversion coefficients were derived from the 1988-2017 China Energy Statistical Yearbook. $C_{j}$ represents the carbon emissions coefficient corresponding to energy $j$, with data from the IPCC Guidelines for National Greenhouse Gas Inventory. The conversion coefficients of the standard coal and carbon emissions coefficients are shown in Table 1. The amount of carbon emissions of each province from 1988-2017 can be calculated using formula (18), and the results are shown in Appendix A. Furthermore, according to the amounts of carbon emissions divided by the GDP of each province, the carbon emission intensity can be obtained (Peng et al., 2021). Appendix B 
presents the results.

Insert Table 1 here.

\subsubsection{Control variables}

In addition to the impact of the core variables, control variables also needed to be considered. Based on the existing literature, we selected the level of urbanization, scientific and technological development level, degree of openness to the outside world, and presence of transportation facilities as the control variables in the model, as shown in Table 2. Among them, the level of urbanization is represented by the ratio of the urban population to the total population of each province (Gao et al., 2021). The level of scientific and technological development is represented by the ratio of the expenditures of research and development institutions to the GDP of each province (Liu et al., 2020); the degree of openness to the outside world is expressed by the ratio of foreign direct investment to the GDP of each province (Ramachandran et al., 2020). The presence of transportation facilities is represented by the density of roads (Wang and Han, 2013). The relevant data were mainly derived from the China Statistical Yearbook, China Science and Technology Statistical Yearbook, China Population and Employment Statistical Yearbook, China Transportation Yearbook, and the provincial statistical yearbooks. The missing data were supplemented by interpolation, and the variables of the current price statistics were deflated to the base period level of 1988.

\section{Insert Table 2 here.}

We selected the panel data of 29 Chinese provinces from 1988-2017, excluding Chongqing, Tibet, Hong Kong, Macao, and Taiwan (China) ${ }^{5}$ for empirical analysis. Table 3 reports the descriptive statistics and collinearity test results for the main variables. First, based on the overall level, the mean value of $E M$ is 2.018, indicating that the overall level of SMEPRs is excessive. The mean value of variable LNCEI is 1.684. It is much higher than that of developed countries such as the US and Japan and countries such as Brazil and Mexico, whose per capita GDPs are like that of China (Li and Qin, 2019). This means that the current pressure to reduce carbon emissions in China is still high. The average TFP value is 0.991 , which is under 1 , indicating that the most efficient production conditions have not been reached overall. Second, from the dispersion level, there are varying degrees of differences in carbon emissions, economic efficiency, and the level of SMEPRs among provinces. This difference also proves that there are many problems in China's rapid development. For example, the difference between the provinces with the highest (Inner Mongolia) and lowest carbon emissions intensity (Hainan) is about 125 times. The difference between the provinces with the highest TFP and the province with the lowest is 5.5 times. The province with the highest degree of over-allocation of electric power resources (Guizhou) has a value of 13.925, while that with the greatest under-allocation (Hainan Province) has only 0.185. Finally, the dispersion coefficients of the control variables are mostly relatively high. This indicates that the levels of urbanization and technological development are significant differences among provinces. And this is consistent with the imbalances in China's regional economic development.

${ }^{5}$ Because Chongqing only became a municipality under the Central Government in 1997, and the data of Tibet fluctuated greatly and are unavailable, the data of Chongqing and Tibet were excluded from the empirical study. In addition, since the variable coefficient model is applicable to long panel data, the data of 30 years from 1988-2017 have been used in this paper. 
Moreover, we investigated the variance expansion factor of the explanatory variables and found that the VIF value of each variable is under 10 , and the mean value is under 2 . Therefore, it can be concluded that there was no multicollinearity among the explanatory variables.

\section{Insert Table 3 here.}

\section{Results and discussion}

\subsection{Data validation and parameter estimation results}

The panel data include both cross-sectional and time-series data. Unsteady time series may cause pseudo-regression problems; therefore, panel unit root tests needed to be performed (Im et al., 2003). If there is cross-sectional dependency, the traditional Levin-Lin-Chu test and Augmented Dicky-Fuller test are not convincing. So the cross-sectional dependency test (Pesaran-CD test) is performed before the unit root test. The results are listed in Table 4. The test results show that the null hypothesis that no cross-sectional dependency is rejected at a significance level of $1 \%$. Therefore, the Pesaran-CADF test considering cross-sectional dependency is selected for the unit root test, and the results are shown in Table 5. The null hypothesis of the test is to have unit-roots. It can be seen from the results in Table 5 that although some series are not stable, all the difference series reject the null hypothesis. The panel data of non-stationary time series can be converted into stationary ones by difference. However, in this way, a large amount of information inevitably gets lost. The best way to deal with this problem is to perform a cointegration test. If the data are cointegrated, their linear combination can become stable, and the variable coefficient panel estimation can be carried out directly. Based on this connection, we further adapted the Pedroni and Kao tests to test the cointegration relationship (Greene, 2011), and the results are shown in Table 6. The P-values of the four statistics in the Pedroni test (i.e., Panel PP-statistic, Panel ADF-statistic, Group PP-statistic, and Group ADF-statistic) are all under 0.05. Therefore, it can be concluded that the Pedroni test rejected the null hypothesis that there is no cointegration relationship. The KAO test results show that the test value is 1.594 , and the associated probability is 0.055 , indicating a cointegration relationship between the variables. In summary, we can perform a variable coefficient panel estimation.

\section{Insert Tables. 4, 5, and 6 here.}

Considering the heteroscedasticity between the individuals in the panel data, we used the panel calibration standard error (PCSE, cross-section weights) to overcome the cross-sectional heteroscedasticity problem of the random error term. According to the calculation steps above, the estimated elastic coefficients of each production factor can be obtained, as shown in Table 7. The results show that the overall goodness of fit of the model was 0.985 , and the F-statistic value was 445.421 . The regression coefficients of each province passed the significance test, indicating that the overall model results were reliable.

\section{Insert Table 7 here.}

\subsection{Measurement results and discussion of SMEPRs}

The level of SMEPRs in the 29 provinces from 1988-2017 was calculated using the model proposed in Section 3.1. 
The results are shown in Appendix C. The results of SMEPRs was divided into three categories. The spatial allocation degree of electric power resources is greater than or equal to 0 and less than 0.8 is insufficient allocation, greater than or equal to 0.8 and less than 1.2 is reasonable allocation ${ }^{6}$, and greater than or equal to 1.2 is excessive allocation. On this basis, we analyzed the spatiotemporal pattern and evolution of SMEPRs. The results are shown in Figures 2 to 5.

Figure 2 shows the overall situation of SMEPRs in 29 provinces across the country and the fluctuation trends in each period. From the overall situation, the median level of SMEPRs per year was greater than 1. This shows that the overall situation regarding power resources in China indicates a state of overallocation. This is also consistent with the fact that China's coal power situation indicates overcapacity (Wang et al., 2018). From the fluctuation trends of SMEPRs, the degree of SMEPRs formed four peaks from 1988-2017 and occurred around 1991, 1999, 2005 , and 2012. This is consistent with China's economic and transitional cycles. ${ }^{7}$ And since 2008, the median and interquartile differences in the degree of SMEPRs show a relatively apparent upward trend. This indicated that the overall level of and spatial differences in SMEPRs have gradually increased.

\section{Insert Fig. 2 here.}

Figures 3 and 4 show the overall situation and evolutionary trend of SMEPRs at the regional and provincial scales, respectively. Combining Figures 3 and 4, the degree of SMEPRs shows significant spatiotemporal heterogeneity, both in the regions and provinces. Specifically, from a regional perspective, ${ }^{8}$ SMEPRs in western China are always higher than in eastern and central. Before 1993, the degree of SMEPRs in the central region was higher than in the eastern. Afterwards, however, the degree in the eastern region became higher than that of the western. Meanwhile, the degree of SMEPRs in the eastern and western regions showed an upward trend over time. In contrast, it showed a downward trend in the central region, and the allocation of electric power resources gradually tended to be rational. From a provincial perspective, the degree of SMEPRs in Beijing, Tianjin, Zhejiang, and Fujian in the eastern region gradually strengthened (Zhejiang and Fujian were severe cases). Hainan showed a downward trend, and the other six provinces always exhibited a low degree. In the central region, the degree of SMEPRs in Jilin and Hubei gradually increased. Although the degree of SMEPRs in Shanxi Province was gradually decreasing, it remained high. The other four provinces showed slight fluctuation, and their degree was low. In the western region, the degree of SMEPRs in Xinjiang, Inner Mongolia, Sichuan, and Qinghai was continuously increasing, while in Shaanxi and Gansu, it was weakening. The

\footnotetext{
${ }^{6}$ Reasonable allocation of resources refers to an optimal allocation state where resources can flow freely, achieve Pareto optimality, and maximize the total output of society. Based on the setting of the SMEPRs calculation model and its results, this paper set the level of SMEPRs within the interval $[0.8,1.2)$ as a reasonable allocation.

7 Yushu Cao and Dongwei Lou (2012) used Lilien's Index to calculate and analyze the flow of factors in China since 1978. On this basis, they identified China's economic transition cycle and found the synchronization correlation between the transitional and economic cycles.

8 With reference to the National Development and Reform Commission, in this paper, the 29 provincial-level administrative regions (except Chongqing and Tibet) were divided into three major regions: eastern, central, and western. Among them, the eastern region includes Beijing, Tianjin, Hebei, Liaoning, Shanghai, Jiangsu, Zhejiang, Fujian, Shandong, Guangdong, and Hainan; the central region includes Shanxi, Jilin, Heilongjiang, Anhui, Jiangxi, Henan, Hubei, and Hunan; the western region includes Inner Mongolia, Sichuan, Guizhou, Yunnan, Shaanxi, Gansu, Guangxi, Qinghai, Ningxia, and Xinjiang. For convenience, the 29 provincial administrative regions are collectively referred to as "provinces" below.
} 
remaining four provinces had a slight change in the degree. The possible reasons for these results are as follows. First, since China implemented the "great western development strategy" in March 2000, the scale of investment in the coal and thermal power industries in the western region has been continuously expanding. Moreover, the region's level of economic development has gradually improved. However, due to geographical conditions and other aspects, its economic growth mode has long been driven mainly by extensive investment. And the endogenous investment motivation and innovation capability of the market are insufficient. All these factors have led to low factor productivity and the long-term overallocation of electric power resources. Second, despite the relatively high level of economic development in the eastern, under the dual effects of the "West-East Power Transmission" project and the explosive growth of renewable energy investment, the eastern region, especially in terms of its power resources, also shows signs of being in excessive allocation. Finally, in March 2004, China implemented a development strategy in central China and increased policy support for the central region. This has significantly promoted the economic development of the central region, and the demand for power resources has overgrown. This means that the central region's economic development level has begun to match the allocation of electric power resources gradually. The above results show that in implementing major national projects, there are always pros and cons coexisting. For example, the "West-East Power Transmission" project has driven the flow of electric power resources and the economic development of some regions. However, let us only consider increasing the allocation of electric power resources and ignore the effective utilization of resources. It will only do more harm than good in the long run.

\section{Insert Figs. 3 and 4 here.}

Figure 5 shows the overall situation and evolution of trends in the direction of SMEPRs at the provincial level. It can be observed that the provinces that have always been over-allocated with electric power resources include Shanxi, Inner Mongolia, Zhejiang, Fujian, Guangxi, Guizhou, Qinghai, Ningxia, and Xinjiang. These provinces have developed heavy and chemical industries with a single industrial structure and rich natural resources. The existing evidence shows that long-term reliance on excessive resources to seek regional economic growth will severely restrict sustainable development and the development of high-tech industries. (Badeeb et al., 2017). Beijing, Tianjin, Hubei, Hainan, and Sichuan are among the provinces that have consistently suffered from insufficient allocation of electric power resources. These provinces have a high level of economic development (such as Beijing) or very few electric power resources (such as Hainan). Sichuan and Hubei are the provinces with the largest hydropower installed capacity in China, ranking in the top 10 in China's total economic output. However, they are also the provincial power grid with the most outgoing power, whose power consumption does not match the economic development. Hebei, Shandong, Henan, and Yunnan are the four provinces that have always remained within a reasonable range. Six provinces have changed from irrational to rational allocation. Heilongjiang, Shanghai, Jiangxi, Shaanxi, and Gansu have changed from excessive to rational allocation, and Jiangsu has changed from insufficient to rational allocation. This mainly stems from the "West-East Power Transmission" project, which has promoted the flow of electric power resources. The provinces that have evolved from rational to irrational allocation include Liaoning, Jilin, and Hunan, and all of which have changed from rational to insufficient allocation. Guangdong went from insufficient to excessive. Given that Guangdong was included 
in the first batch of reform and opening-up policies in manufacturing provinces, since participating in the "West-East Power Transmission" project, it has become the province with the greatest amount of investment. It has received the most power from the West. ${ }^{9}$ Therefore, in the allocation of electric power resources, not only the electric power demand of the province must be considered, but also the province's economic development to avoid over-allocation.

\section{Insert Fig. 5 here.}

\subsection{The mediating effect test of SMEPRs on economic efficiency}

To investigate the transmission mechanism that SMEPRs affects economic efficiency through the industrial structure, we chose the proportion of the added value of secondary industries to the GDP as the mediator to conduct the mediation effect test. Table 8 reports the two-dimensional fixed-effects estimation results using the panel data model. Wooldridge's "robust Hausman test" was used to select the fixed- or random-effects model. Table 9 reports the test results obtained by bootstrap sampling with TFP as the explained variable and $I S$ as the intermediary variable.

The regression results in column (1) of Table 7 show that $E M$ harms TFP. Its estimated coefficient is -0.043 , but it is not significant. The existing studies have pointed out that the significant correlation between independent and dependent variables should not be taken as a precondition for studying mediation effects (MacKinnon et al., 2000; Zhao et al., 2010). Therefore, we followed the approach of Zhao et al. (2010) and continued to test the mediation effect. The regression results in column (3) of Table 7 show that the estimated coefficient of $E M$ is 34.652, which is significant at the $1 \%$ level. A possible reason for this result is that the electric power price in a specific province can be easily distorted and underestimated when the degree of electric power resources allocation is high. As a result, industrial enterprises, especially energy-intensive ones, are attracted to agglomerate. And the added value of secondary industries increases as a percentage of the GDP. For example, the power resources in Shanxi Province are over-allocated, and the misallocation degree is always serious. Correspondingly, the industrial structure in Shanxi is relatively simple, and the heavy chemical industry accounts for a relatively high proportion of the total.

Column (2) of Table 7 shows the regression results after adding the intermediary variables. It can be seen that the estimated coefficient of $E M$ is still negative, but it is not statistically significant. The estimated coefficient of $I S$ is 0.0011 , which is significant at the $1 \%$ level. Previous studies have shown that industrial agglomeration can promote TFP growth to some extent (Geppert et al., 2008). Combined with the results in Table 8, the bootstrap test shows that the mediation effect of electric power resource allocation on TFP through industrial structure is significant. The signs of direct and indirect effects are opposite, but the direct effect $E M$ of TFP is not significant. The result indicates that the impact of the level of power resource allocation on TFP is not direct but is formed through the mediator of industrial structure. In addition, the opposite sign of direct and indirect effects indicates that the excessive allocation of electric power resources inhibits the improvement of TFP. But the industrial structure, as a mediator, weakens the negative impact of the excessive allocation of electric power resources on TFP to some extent. This result is consistent with the conclusion that resource misallocation hinders the improvement of economic efficiency. At the same time, the above results reveal the internal transmission mechanism of resource misallocation affecting TFP. That is, the SMEPRs will

9 Source: CCTV International Network, http://www.cctv.com/special/777/2/52418.html. 
inhibit the adequate flow of production factors, and excessive electric power resources will cause the accumulation of energy-intensive enterprises. They often rely excessively on the advantages of electric power resources and lack sufficient motivation to carry out technological innovations, thereby inhibiting the increase in TFP.

\section{Insert Tables. 8 and 9 here.}

\subsection{Test of the mediating effect of SMEPRs on carbon emissions}

To investigate the transmission mechanism underlying how SMEPRs affects carbon emissions through the regional industrial structure, we chose the proportion of the added value of secondary industries to the GDP as the mediator to conduct the mediation effect test. Table 10 reports the two-dimensional fixed-effects estimation results using the panel data model. Wooldridge's "robust Hausman test" was used to select the fixed- or random-effects model. Table 11 reports the test results obtained by bootstrap sampling with $L N C E$ and $L N C E I$ as the explained variables and IS as the intermediary variable.

The regression results in columns (1) and (3) of Table 9 show that the regression coefficients of $L N C E$ and LNCEI to EM are 2.698 and 2.822, respectively, and they are significant at the $1 \%$ level. A possible reason is that the power sector is the largest contributor to carbon emissions, and an excessive accumulation in the sector leads to the growth of regional carbon emissions. The regression results in column (5) of Table 10 show that the estimated coefficient of $E M$ is 34.652, which is significant at the $1 \%$ level. Moreover, as shown in columns (2) and (4) of Table 10, the regression coefficients of LNCE and LNCEI to EM are 2.182 and 2.370, respectively. And they decreased by 0.516 and 0.452 , respectively, compared to those without the intermediary variable. The regression coefficients of the intermediary variable $I S$ are 0.015 and 0.013 , respectively. The above coefficients are all significant at the $1 \%$ level. Combined with Table 11, the bootstrap test results show that the mediation effect is significant. The above results confirm that the industrial structure is an important path for the excessive allocation of electric power resources to aggravate carbon emissions. Moreover, the mediating effects of $E M$ on $L N C E$ and LNCEI through industrial structures accounted for $23.64 \%$ and $19.16 \%$ of the impact, respectively. This implies that $23.64 \%$ of the impact of power resource allocation on the amount of carbon emissions and $19.16 \%$ of its impact on carbon emissions intensity are generated through the industrial structure. Excessive allocation of electric power resources often leads to the accumulation of high-energy-consuming enterprises. Thereby increase the proportion of the added value of the regional secondary industry in GDP. Existing studies have proved that the share of the secondary industry has a significant positive impact on carbon emissions. As a result, the excessive allocation of electric power resources aggravates the carbon emissions, either directly affecting or through the industrial structure.

\section{Insert Tables. 10 and 11 here.}

\subsection{Robustness Checks}

\subsubsection{Substitution of explanatory variables}

To verify the reliability of the regression results, we used dummy variables to represent SMEPRs. According to the proposed power resource spatial misallocation calculation model, the variable EM contains three levels. That is the 
insufficient allocation $(0 \leq E M<0.8)$, rational allocation $(0.8 \leq E M<1.2)$, and excessive allocation $(E M \geq 1.2)$ of electric power resources. Correspondingly, two dummy variables were introduced: $M 1$ and $M 2$. The specific assignments were as follows: When the power resource allocation is insufficient, $M 1$ and $M 2$ are assigned values of 1 and 0, respectively. When the power resource allocation is rational, both $M 1$ and M2 are assigned values of 0 . When the power resource allocation is excessive, $M 1$ and $M 2$ are assigned values of 0 and 1, respectively. Accordingly, dummy variables were substituted for explanatory variables in the stepwise regression analysis.

Table 12 reports the two-dimensional fixed-effects regression results under the ordinary panel data model. The spatial allocation of electric power resources affects TFP, LNCE, and LNCEI through the industrial structure. And the explanatory variable is a dummy variable. In Table 12, columns (1), (3), and (5) are the results of the direct regression of TFP, LNCE, and LNCEI on the level of SMEPRs, respectively; columns (2), (4), and (6) list the regression results after adding the intermediary variable of industrial structure; and column (7) lists the regression results of industrial structure on the level of SMEPRs. The results show that when the explained variable is TFP, the estimated coefficient of M1 is 0.017 , and it is significant at the $10 \%$ level. The estimated coefficient of $M 2$ is 0.011 , but it is not statistically significant. When the explained variable is $L N C E$, the estimated coefficients of the variables $M 1$ and $M 2$ are -0.150 and 0.205 , respectively; when the explained variable is $L N C E I$, the estimated coefficients of the variables $M 1$ and $M 2$ are -0.149 and 0.147 , respectively. The above coefficients are all significant at the $1 \%$ level. The above results show that the TFP with an insufficient allocation of electric power resources is slightly higher than those with a rational allocation. The $L N C E$ and $L N C E I$ values of regions with an insufficient allocation of electric power resources are lower than those of regions with a rational allocation. The LNCE and LNCEI values of regions with an excessive allocation of electric power resources are higher than those of regions with a rational allocation. After adding the intermediary variables, the explained variables are TFP, LNCE, and LNCEI, and the estimated coefficients of the corresponding $I S$ are $0.001,0.018$, and 0.016 , and they are significant at the levels of 5\%, $1 \%$, and $1 \%$, respectively. The estimated coefficients of the corresponding $M 1$ are $0.017,-0.147$, and -0.146 , and they are significant at the levels of $10 \%, 1 \%$, and $1 \%$, respectively. The estimated coefficients of the corresponding $M 2$ are $0.005,0.101$, and 0.050 . The estimated coefficient is significant at the 5\% level only when the explained variable is $L N C E$. The above results show that, after adding the intermediary variable $I S$, the proportion of the added value of secondary industries to the GDP positively affects TFP, LNCE, and LNCEI. The remaining results are essentially consistent with the results without the intermediary variable $I S$. According to the robustness test results, the conclusions of this study are reliable.

\section{Insert Table 12 here.}

\subsubsection{Substitution of the mediator}

Referring to Guo and Wang (2013), we further used the proportion of industrial added value to the GDP (IS2) to measure the industrial structure. The results are presented in Tables 13 and 14. Comparing Tables 8-11 with Tables 13 and 14, we found that the signs and significance levels of the regression coefficients of all the variables are consistent with the previous ones. Therefore, the regression results based on the new intermediary variables show that the 
conclusions of this study are robust. Owing to space limitations, the details are not repeated.

\section{Insert Tables. 13 and 14 here.}

\section{Conclusion and policy implications 6.1 Key conclusions}

Based on the fact that the electric power market has not yet been fully market-oriented in China, this paper constructed a calculation model for SMEPRs. The degree, direction and trend of SMEPRs had been analyzed. On this basis, it has empirically investigated the influence and transmission mechanism of SMEPRs with regional economic efficiency and carbon emissions. The main conclusions are as follows.

First, the level of SMEPRs in China is relatively high and presents significant spatiotemporal heterogeneity. In terms of spatial dimensions, the average level of SMEPRs is medium-to-high overall. In comparison, the degree of SMEPRs is the highest in the western region, followed by the eastern region, and it is the lowest in the central region. In terms of the time dimension, the fluctuation trend of the average level of SMEPRs from 1988 - 2017 was relatively stable. Nevertheless, there was also significant heterogeneity among the regions. Among them, the degree of SMEPRs in the eastern and western regions appeared to be on the rise, while, in the central region, there appears to be a trend of improvement. This conclusion indicates that the governance related to China's electric power resource misallocation problem needs to be implemented following local conditions and trends.

Second, SMEPRs has a significant negative impact on regional economic efficiency. But this effect is indirect and mainly occurs through the industrial structure. Specifically, the excessive allocation of electric power resources inhibits the growth of economic efficiency. However, since industrial agglomeration can promote the improvement of TFP, the industrial structure as an intermediary variable weakens the negative impact of the excessive allocation of electric power resources on TFP. This conclusion shows that SMEPRs is an important factor that restricts the high-quality development of regional economies.

Third, SMEPRs has a significant direct impact on regional carbon emissions and has an indirect impact through the industrial structure. The more serious the over-allocation of electric power resources is, the higher the proportion of the added value of the secondary industries in GDP. And the regional carbon emissions and carbon emissions intensity will increase accordingly. This suggests that regional industrial layouts and structural optimization should be considered in the governance process of SMEPRs. Furthermore, this should be taken as the focus to improve economic efficiency and reduce carbon emissions.

\subsection{Policy implications}

According to the conclusions of this study, the problem of SMEPRs in China is still serious and will likely continue to be in the future. And it currently has a significant negative impact on regional economic efficiency and carbon emissions. Therefore, we propose the following policy implications.

Efforts should be made to continue deepening reforms to the power system and gradually promote a national electricity market. China should strive to break the current inter-provincial monopoly in the electricity market. Moreover, the unrestricted flow and optimal allocation of electric power resources across the country should be promoted. First, it will be necessary to provide a solid platform for achieving cross-regional allocation optimization. In 
particular, the construction of power grid infrastructure should be accelerated, especially in the construction of ultra high voltage direct current transmission channels and alternating current synchronous power grids. Enhance the transmission capacity of cross-regional power grids. Second, it will be necessary to provide a sound system and mechanism to guarantee the optimal allocation of electric power resources across regions. Concretely, efforts should also be made to establish a national power system and construct power transmission channels and other coordination mechanisms. To accelerate the promotion of the national power resource interconnection and break provincial and regional monopolies. Eventually, a unified, open, and orderly competitive national electricity market system will be formed. Finally, it must be pointed out that cross-regional transactions are restricted by transmission channel capacity constraints and market access restrictions. It would be not easy to achieve a truly unified national electricity market in the short term. Therefore, the government should follow geographical proximity and resource complementarity principles to build several inter-provincial regional electricity markets. The regional electricity market will gradually become integrated, and a unified national electricity market will be formed. For example, Sichuan and Guizhou, two provinces with complementary electric power resource allocations, could be selected as pilot areas to establish a platform. This may provide effective institutional conditions and guarantees for realizing the region's market-oriented flow of electric power resources.

From a regional perspective, the government should formulate targeted policies according to the actual situation. For provinces with an over-allocation of electric power resources (such as Shanxi and Inner Mongolia), on the one hand, the government should formulate strict market access conditions and environmental protection policies. And then accelerate the transformation of related industries from extensive to intensive development models. On the other hand, the comprehensive use of credit, taxation, and depreciation would force energy-intensive enterprises to implement technological transformations and upgrades. The backward, inefficient, and environmentally unfriendly industry will be gradually eliminated, and the regional industrial structure will be continuously optimized. For provinces with insufficient power resource allocation (such as Beijing, Tianjin), on the one hand, clean power industries such as wind and photovoltaic power should be actively developed. And distributed photovoltaic facilities should be built according to local conditions. On the other hand, it will be necessary to coordinate the regional industrial layout and fully play to regional advantages. High-end manufacturing with high technology, high information intensity, and strong driving ability should be actively developed to promote regional industrial upgrading and restructuring.

\subsection{Outlook}

This paper measured the spatial misallocation of electric power resources in China. Furthermore, its spatiotemporal patterns and its impact on economic efficiency and carbon emissions were analyzed. This deepens our understanding of the SMEPRs and its impact, but there are also some limitations. For example, the calculation model of SMEPRs was based on the assumption of constant return to scale, and the results might be sensitive to small changes. In future research, we will try to pay more attention to these problems.

\section{Figure legends:}

Fig. 1 Effects of the spatial mismatch of power resources on economic efficiency and carbon emissions Fig. 2 Comparison of the level of SMEPRs from 1988-2017 
666 Fig. 3 The evolution of trends in SMEPRs at the regional level

667 Fig. 4 The evolution of trends in the degree of SMEPRs at the provincial level

668 Fig. 5 The evolution trends in the direction of SMEPRs at the provincial level 
Aoki, S. 2012. A simple accounting framework for the effect of resource misallocation on aggregate productivity. Journal of the Japanese and International Economies, 26(4), 473-494.

Badeeb, R. A., Lean, H. H., \& Clark, J. 2017. The evolution of the natural resource curse thesis: A critical literature survey. Resources Policy, 51, 123-134.

Banerjee, A. V., \& Moll, B. 2010. Why does misallocation persist?. American Economic Journal: Macroeconomics, 2(1), $189-206$.

Brandt, L., Tombe, T., \& Zhu, X. 2013. Factor market distortions across time, space and sectors in China. Review of Economic Dynamics, 16(1), 39-58.

Brandt, L., Van Biesebroeck, J., \& Zhang, Y. 2012. Creative accounting or creative destruction? Firm-level productivity growth in Chinese manufacturing. Journal of Development Economics, 97(2), 339-351.

680 Chen, L., Xu, L., Cai, Y., \& Yang, Z. 2021. Spatiotemporal patterns of industrial carbon emissions at the city level. Resources,

682 Chen, Y. W., \& Hu, W. M. 2011. Distortions, misallocation and losses: theory and application. China Economic Quarterly, 10(4), 683 1401-1422. (In Chinese)

684 Choi, B. 2020. Productivity and misallocation of energy resources: Evidence from Korea's manufacturing Sector. Resource and 685 Energy Economics, 61, 101184.

686 Chu, X., Geng, H., \& Guo, W. 2019. How does energy misallocation affect carbon emission efficiency in China? An empirical study 687 based on the spatial econometric model. Sustainability, 11(7), 2115.

ELLIOTT, R. J., \& Shanshan, W. U. 2008. Industrial activity and the environment in China: an industry-level analysis. China Economic Review, 19(3), 393-408.

Feng, C., Huang, J. B., \& Wang, M. 2018. Analysis of green total-factor productivity in China's regional metal industry: A 691 meta-frontier approach. Resources Policy, 58, 219-229.

692

Freeman, R. 2019. Doubling the global workforce: the challenges of integrating China, India, and the former Soviet block into the world economy. Doubling the Global Work Force".

Gao, Y., Zhang, M., \& Zheng, J. 2021. Accounting and determinants analysis of China's provincial total factor productivity considering carbon emissions. China Economic Review, 65, 101576.

Geppert, K., Gornig, M., \& Werwatz, A. 2008. Economic growth of agglomerations and geographic concentration of industries: Evidence for West Germany. Regional Studies, 42(3), 413-421.

GUO, G. F., \& WANG, Y. P. (2013). Analysis on the Potential and Target of China's Industrial Energy-saving in 12th Five-Year Plan Period (2011-2015). China Industrial Economics, 3. (In Chinese)

Haley, U. C., \& Haley, G. T. 2013. Subsidies to Chinese industry: State capitalism, business strategy, and trade policy. Oxford University Press.

Hao, Y., Gai, Z., \& Wu, H. 2020. How do resource misallocation and government corruption affect green total factor energy efficiency? Evidence from China. Energy Policy, 143, 111562.

Hsieh, C. T., \& Klenow, P. J. 2009. Misallocation and manufacturing TFP in China and India. The Quarterly Journal of Economics, 124(4), 1403-1448.

Hu, Y., Deng, T., \& Zhang, J. 2020. Can commuting facilitation relieve spatial misallocation of labour?. Habitat International, 106, 102136.

Huang, Z., \& Du, X. 2017. Government intervention and land misallocation: Evidence from China. Cities, 60, 323-332.

Im, K. S., Pesaran, M. H., \& Shin, Y. 2003. Testing for unit roots in heterogeneous panels. Journal of Econometrics, 115(1), 53-74. 
Jun, Z., Guiying, W., \& Jipeng, Z. 2004. The Estimation of China's provincial capital stock: 1952-2000. Economic Research Journal, 10(1), 35-44. (In Chinese)

Karabarbounis, M., \& Macnamara, P. 2021. Misallocation and financial frictions: The role of long-term financing. Review of Economic Dynamics, 40, 44-63.

Kong, Q., Peng, D., Ruijia, Z., \& Wong, Z. 2021. Resource misallocation, production efficiency and outward foreign direct investment decisions of Chinese firms. Research in International Business and Finance, 55, 101343.

Li, H., \& Qin, Q. 2019. Challenges for China's carbon emissions peaking in 2030: A decomposition and decoupling analysis. Journal of Cleaner Production, 207, 857-865.

Li, X., Liu, X., \& Wang, Y. 2012. A model of China's state capitalism. Available at SSRN.

Liu, H., Zhang, Z., Zhang, T., \& Wang, L. 2020. Revisiting China's provincial energy efficiency and its influencing factors. Energy, 208, 118361.

LIU, Z. M., \& WU, Z. Q. 2019. Will Intermediate Product Market Distortion Hinder the Improvement of Total Factor Productivity in Energy Industry: A Theoretical and Empirical Research Based on Micro-enterprise Data. China Industrial Economics, 08. (In Chinese)

MacKinnon, D. P., Krull, J. L., \& Lockwood, C. M. 2000. Equivalence of the mediation, confounding and suppression effect. Prevention science, 1(4), 173-181.

Oberfield, E. . 2013. Productivity and misallocation during a crisis: evidence from the chilean crisis of 1982. Review of Economic Dynamics, 16(1), 100-119

Pedroni, M., Tamassia, M. G., Percesepe, A. et al. 1999. Microsatellite instability in multiple colorectal tumors. International Journal of Cancer, 81(1), 1-5.

Peng, X., Tao, X., Zhang, H., Chen, J., \& Feng, K. 2021. CO2 emissions from the electricity sector during China's economic transition: from the production to the consumption perspective. Sustainable Production and Consumption, 27, 1010-1020.

Ramachandran, R., Sasidharan, S., \& Doytch, N. 2020. Foreign direct investment and industrial agglomeration: Evidence from India. Economic Systems, 44(4), 100777.

Sun, C., Zhan, Y., \& Du, G. 2020. Can value-added tax incentives of new energy industry increase firm's profitability? Evidence from financial data of China's listed companies. Energy Economics, 86, 104654.

Syrquin, M. . 1984. Resource reallocation and productivity growth. Economic Structure and Performance, 75-101.

Teng, F., Jotzo, F., \& Wang, X. 2017. Interactions between market reform and a carbon price in China's power sector. Economics of Energy \& Environmental Policy, 6(2), 39-54.

Wang, D., Wang, Y., Song, X., \& Liu, Y. 2018. Coal overcapacity in China: Multiscale analysis and prediction. Energy Economics, 70, 244-257.

Wang, F., \& Han, X. 2013. Research on the optimal density of highway network. Procedia-Social and Behavioral Sciences, 96, 1556-1565.

Wang, S., Li, C., \& Zhou, H. 2019. Impact of China's economic growth and energy consumption structure on atmospheric pollutants: Based on a panel threshold model. Journal of Cleaner Production, 236, 117694.

Wang, S., Zhao, D., \& Chen, H. 2020. A spatial analysis of corruption, misallocation, and efficiency. Environmental Science and Pollution Research, 27(29), 36845-36856.

Wei, C., \& Li, C. Z. 2017. Resource misallocation in Chinese manufacturing enterprises: evidence from firm-level data. Journal of Cleaner Production, 142, 837-845.

Wu, G. L. 2018. Capital misallocation in China: Financial frictions or policy distortions?. Journal of Development Economics, 130, $203-223$. 
Wu, J., Wu, Y., \& Wang, B. 2018. Local government debt, factor misallocation and regional economic performance in China. China \& World Economy, 26(4), 82-105.

Xu, L., \& Tan, J. 2020. Financial development, industrial structure and natural resource utilization efficiency in China. Resources Policy, 66, 101642.

Yang, C. H., \& Lee, W. C. 2021. Establishing science parks everywhere? Misallocation in R\&D and its determinants of science parks in China. China Economic Review, 67, 101605.

Yang, M., Yang, F., \& Sun, C. 2018. Factor market distortion correction, resource reallocation and potential productivity gains: An empirical study on China's heavy industry sector. Energy Economics, 69, 270-279.

Zhang, J., Jin, W., Philbin, S. P., Lu, Q. C., Ballesteros-Pérez, P., Skitmore, M., \& Li, H. 2021. Impact of environmental regulations on carbon emissions of transportation infrastructure: China's evidence. Cleaner and Responsible Consumption, 2, 100010.

Zhao, X., Lynch Jr, J. G., \& Chen, Q. 2010. Reconsidering Baron and Kenny: Myths and truths about mediation analysis. Journal of consumer research, 37(2), 197-206.

Zheng, Q., Jiang, G., Yang, Y., Zhou, D., \& Qu, Y. 2020. Does spatial equilibrium of factor allocation inevitably bring about high benefits for regional development? An empirical study of the Beijing-Tianjin-Hebei region, China. Habitat International, 95, 102066.

Zhou, Z., Chen, Y., Song, P., \& Ding, T. 2020. China's urban air quality evaluation with streaming data: A DEA window analysis. Science of the Total Environment, 727, 138213. 


\section{Declaration}

Ethics approval and consent to participate

We declare that we do not have human participants, human data, or human tissue involved in the study.

\section{Consent for publication}

Not applicable

\section{Competing interests}

The authors declare that they have no known competing financial interests or personal relationships that could have appeared to influence the work reported in this paper.

\section{Availability of data and materials}

The datasets used and/or analysed during the current study are available from the corresponding author on reasonable request.

\section{Acknowledgments}

This research is supported by the National Natural Science Foundation of China (No. 71573252; No. 72074210) and Social Science Foundation of Jiangsu Province (No. 18JD014).

\section{Authors' contributions}

Delu Wang: Conceptualization, Methodology, Validation, Resources, Writing- Review \& Editing.

Suqing Zhang: Software, Formal analysis, Investigation, Data Curation, Writing-Original Draft.

Yadong Wang: Data Curation, Writing-Original Draft.

Jinqi Mao: Software, Formal analysis.

\section{Authors' information:}


Author 1 Name: Delu Wang

Department: School of Economics and Management

University/Institution: China University of Mining and Technology

Town/City: Xuzhou 221116

Country: P. R. China

Author 2 Name: Suqing Zhang

Department: School of Economics and Management

University/Institution: China University of Mining and Technology

Town/City: Xuzhou 221116

800

Country: P. R. China

Author 3 Name: Yadong Wang

Department: School of Economics and Management

University/Institution: China University of Mining and Technology

Town/City: Xuzhou 221116

Country: P. R. China

Author 4 Name: Jinqi Mao

Department: School of Economics and Management

University/Institution: China University of Mining and Technology

Country: P. R. China

\section{Corresponding author:}

Delu Wang, dlwang@cumt.edu.cn

\section{Biographical Details:}

Delu Wang is a professor at School of Management, China University of Mining and Technology. His publications have appeared in journals such as Energy Economics, Energy Policy, Technovation, Journal of Forecasting, Journal of Cleaner Production, etc. His research interests include energy conomics.

Suqing Zhang is a doctor candidate at Management School, China University of Mining and Technology. She has co-authored articles in major journals in energy. She is interested in energy policy. 
Yadong Wang is a doctor candidate at Management School, China University of Mining and Technology. She has

821 co-authored articles in major journals in energy. She is interested in energy economics.

822 Jinqi Mao is a doctor candidate at Management School, China University of Mining and Technology. She has co-authored articles in major journals in energy. She is interested in environmental economics and econometric model.

824

\section{Table 1}

Conversion coefficient of standard coal and carbon emissions coefficient

\begin{tabular}{|c|c|c|c|c|c|c|c|c|}
\hline Types of energy & coal & coke & crude oil & gasoline & kerosene & diesel & fuel oil & $\begin{array}{l}\text { natural } \\
\text { gas }\end{array}$ \\
\hline $\begin{array}{l}\text { Conversion coefficient of } \\
\text { standard coal }\end{array}$ & 0.7143 & 0.9714 & 1.4286 & 1.4714 & 1.4717 & 1.4571 & 1.4286 & 1.3300 \\
\hline carbon emission coefficient & & & & & & & & \\
\hline $\begin{array}{l}\text { (tons of carbon/tons of } \\
\text { standard coal) }\end{array}$ & 0.7559 & 0.8550 & 0.5857 & 0.5538 & 0.5714 & 0.5921 & 0.6185 & 0.4226 \\
\hline
\end{tabular}

Note: The unit for the conversion coefficient of standard coal and natural gas is $\mathrm{kg} / \mathrm{m}^{3}$, and the rest are given in tons of standard coal/ton.

Table 2 
Level of scientific Control_RD Ratio of the expenditures of research $\quad$ Liu et al., 2020

and technological and development institutions to the GDP

development of each province.

Level of openness Control_Open Ratio of foreign direct investment to the Ramachandran

GDP of each province. $\quad$ et al., 2020

Highway density Control_Highway Number of highway miles per ten Wang and Han, thousand people. 2013

Descriptive statistics and collinearity test of the variables

\begin{tabular}{llllllll}
\multicolumn{7}{c}{ Descriptive statistics and collinearity test of the variables } \\
\hline Variable & Obs & Mean & Std. Dev & $\begin{array}{l}\text { Coefficient } \\
\text { of variation }\end{array}$ & Min & Max & VIF \\
\hline \hline TFP & 870 & 0.991 & 0.074 & 0.074 & 0.252 & 1.400 & $(1.24)$ \\
LNCE & 870 & 8.358 & 1.027 & 0.123 & 3.1869 & 10.584 & $(1.24)$ \\
LNCEI & 870 & 1.684 & 0.600 & 0.356 & -1.157 & 3.670 & $(1.24)$ \\
EM & 870 & 2.018 & 2.373 & 1.175 & 0.185 & 13.926 & 1.08 \\
IS & 870 & 44.555 & 9.025 & 0.203 & 18.429 & 99.037 & 1.04 \\
Control_Urban & 870 & 56.195 & 17.313 & 0.308 & 21.938 & 127.315 & 1.59 \\
Control_RD & 870 & 1.109 & 1.168 & 1.053 & 0.0274 & 8.631 & 1.15 \\
Control_Open & 870 & 0.363 & 0.415 & 1.143 & 0.001 & 2.924 & 1.39 \\
Control_Highway870 & 21.716 & 18.447 & 0.849 & 0.892 & 135.276 & 1.19 \\
\hline
\end{tabular}

\section{Table 3}




\section{Table 4}

Results of the panel cross-sectional dependency test

\begin{tabular}{ccc}
\hline Variable & CD Test & P-value \\
\hline \hline $\ln \mathrm{Y}$ & 108.09 & $0.000^{* * *}$ \\
$\ln \mathrm{C}$ & 109.14 & $0.000^{* * *}$ \\
$\ln \mathrm{C}$ & 66.38 & $0.000^{* * *}$ \\
$\ln \mathrm{C}$ & 109.03 & $0.000^{* * *}$ \\
\hline
\end{tabular}

Note: *,**, and $* * *$ indicate statistical significance at the $10 \%, 5 \%$, and $1 \%$ levels, respectively (the same as in the following table).

\section{Table 5}

Results of the panel unit root test

\begin{tabular}{|c|c|c|c|c|}
\hline Variable & At level & Result & At first difference & Result \\
\hline $\ln \mathrm{Y}$ & -1.695 & $\begin{array}{l}\text { non-stati } \\
\text { y }\end{array}$ & $-3.113 * * *$ & stable \\
\hline $\ln K$ & $-3.385 * * *$ & stable & $-2.513 * * *$ & stable \\
\hline $\ln L$ & -0.563 & $\begin{array}{l}\text { non-stati } \\
\text { y }\end{array}$ & $-3.081 * * *$ & stable \\
\hline $\ln \mathrm{E}$ & -1.801 & $\begin{array}{l}\text { non-stati } \\
\text { y }\end{array}$ & $-3.316 * * *$ & stable \\
\hline
\end{tabular}

\section{Table 6}

Results of panel cointegration tests (after logarithm)

\begin{tabular}{llll}
\hline Testing method & & Statistic & $\boldsymbol{P}$-value \\
\hline \hline \multirow{3}{*}{ Pedroni test } & Modified variance ratio & -4.445 & 0.000 \\
& Modified Phillips-Perron t & 2.909 & 0.002 \\
& Panel PP-Statistic & 1.992 & 0.023 \\
& Panel ADF-Statistic & 2.397 & 0.008 \\
& Modified Phillips-Perron t & 3.896 & 0.000 \\
Kao test & Group PP-Statistic & 1.755 & 0.040 \\
& Group ADF-Statistic & 2.319 & 0.010 \\
& ADF & 1.594 & 0.055 \\
\hline
\end{tabular}




\begin{tabular}{llllllll}
\hline province & $\left|\beta_{E i}\right|$ & province & $\left|\beta_{E i}\right|$ & province & $\left|\beta_{E i}\right|$ & province & $\left|\beta_{E i}\right|$ \\
\hline \hline Beijing & $0.247 * * *$ & Shanghai & $0.256 * * *$ & Henan & $0.450 * * *$ & Guizhou & $0.046 * * *$ \\
& $(93.3495)$ & & $(80.4404)$ & & $(232.1236)$ & $(14.0183)$ \\
Tianjin & $0.623 * * *$ & Jiangsu & $0.515 * * *$ & Hubei & $0.821 * * *$ & Yunnan & $0.396 * * *$ \\
& $(193.9651)$ & & $(201.4069)$ & & $(117.6472)$ & $(199.3616)$ \\
Hebei & $0.507 * * *$ & Zhejiang & $0.081 * * *$ & Hunan & $0.337 * * *$ & Shaanxi & $0.629 * * *$ \\
Shanxi & $(160.4349)$ & & $(5.3216)$ & & $(123.4653)$ & $(179.6234)$ \\
Inner & $0.141 * * *$ & Anhui & $0.509 * * *$ & Guangdong & $0.415 * * *$ & Gansu & $0.551 * * *$ \\
Mongolia & $(27.6196)$ & & $(164.6038)$ & & $(200.2157)$ & $(172.4186)$ \\
Liaoning & $0.518 * * *$ & Jiangxi & $0.297 * * *$ & Hainan & $0.615 * * *$ & Ningxia & $0.228 * * *$
\end{tabular}

Heilongjiang $0.163 * * *$

$(18.4011)$ 
Table 8

\section{Explanatory variables}

\section{TFP}

(1)

$-0.0430$

(0.0551)

IS

EM

\section{Control_Urban}

$$
\begin{aligned}
& -0.0010 * * * \\
& (0.0003)
\end{aligned}
$$

Control_RD

$-0.0037$

(0.0056)

Control_Open

$-0.0097$

(0.0083)

Control_Highway

$0.0005 * *$

(0.0003)

Year-fixed effect

Province-fixed effect

Yes

within $\mathrm{R}^{2}$

Yes

F-statistics

0.375

Robust Hausman

$9.43 * * *$

$30.25 * * *$

Wald1 test

$1179.15^{* * *}$

Wald 2 test

$3.25 *$

Pesaran test

$38.53 * * *$

Group

29

Observations
(2)

$-0.0825$

$(0.0564)$

IS

(3)

$34.6524 * * *$

(4.9750)

$0.0011 * * *$

(0.0004)

$-0.0009 * * *$
$(0.0003)$

$-0.0717 * * *$

(0.0257)

$-0.0055$

$1.6338 * * *$

(0.0056)

(0.5024)

$-0.0114$

$1.4591 *$

(0.0082)

(0.7465)

0.0002

$0.2900 * * *$

(0.0003)

(0.0241)

Yes

Yes

Yes

0.381

Yes

0.659

$9.50 * * *$

$28.15 * * *$

$43.24 * * *$

$39.87 * * *$

$1029.52 * * *$

$3982.19 * * *$

$3.30 *$

2.84*

$39.17 * * *$

$23.58 * * *$

29

29

870

870
900

901

902

903

904

Note: The values in parentheses are standard errors. $R^{2}$ indicates the goodness of fit. "Robust Hausman" refers to the "robust Hausman test” statistic. "Wald1 test” is the Wald test statistic of heteroscedasticity between groups. "Wald2 test" is an intra-group autocorrelation Wald test statistic. The Pesaran test is the test statistic indicating whether the disturbance item is a cross-sectional correlation (the same as in the following table). 


\section{Table 9}

SMEPRs and economic efficiency: test results based on the intermediary effect of industrial structure

\begin{tabular}{llllll}
\hline & $\mathbf{c}$ & c' & $\mathbf{a}$ & b & ab \\
\hline \hline TFP & -0.0430 & -0.0825 & $34.6524 * * *$ & $0.0011^{* * *}$ & 0.038 \\
& $(0.0551)$ & $(0.0564)$ & $(4.9750)$ & $(0.0004)$ & \\
\hline & & Bootstrap-test & & Conclusion \\
\hline TFP & \multicolumn{2}{c}{$95 \%$ Conf. Interval } & Test result & \\
\cline { 3 - 5 } & LLCI & ULCI & & Full mediation \\
\hline
\end{tabular}

907

908

Table 10

Impact of SMEPRs on carbon emissions: regression results considering the industrial structure

\begin{tabular}{|c|c|c|c|c|c|}
\hline \multirow{2}{*}{$\begin{array}{l}\text { Explanatory } \\
\text { variables }\end{array}$} & \multicolumn{2}{|l|}{$L N C E$} & \multicolumn{2}{|l|}{ LNCEI } & \multirow{2}{*}{$\frac{I S}{(5)}$} \\
\hline & (1) & (2) & (3) & $(4)$ & \\
\hline \multirow[t]{2}{*}{$E M$} & $2.6984 * * *$ & $2.1824 * * *$ & $2.8220^{* * * *}$ & $2.3696 * * *$ & $34.6524 * * *$ \\
\hline & $(0.2081)$ & $(0.2004)$ & $(0.2113)$ & $(0.2071)$ & $(4.9750)$ \\
\hline \multirow[t]{2}{*}{$I S$} & & $0.0149 * * *$ & & $0.0131 * * *$ & \\
\hline & & $(0.0014)$ & & $(0.0014)$ & \\
\hline \multirow[t]{2}{*}{ Control_Urban } & $-0.0036^{* * *}$ & $-0.0026^{* *}$ & $-0.0055 * * *$ & $-0.0046^{* * *}$ & $-0.0717 * * *$ \\
\hline & $(0.0011)$ & $(0.0010)$ & $(0.0011)$ & $(0.0010)$ & $(0.0257)$ \\
\hline \multirow[t]{2}{*}{ Control_RD } & 0.0098 & -0.0146 & $0.0738 * * *$ & $0.0524 * *$ & $1.6338 * * *$ \\
\hline & $(0.0210)$ & $(0.0198)$ & $(0.0213)$ & $(0.0204)$ & $(0.5024)$ \\
\hline \multirow[t]{2}{*}{ Control_Open } & $-0.1856^{* * *}$ & $-0.2073 * * *$ & $-0.1877 * * *$ & $-0.2068 * * *$ & $1.4591^{*}$ \\
\hline & $(0.0312)$ & $(0.0293)$ & $(0.0317)$ & $(0.0303)$ & $(0.7465)$ \\
\hline \multirow[t]{2}{*}{ Control_Highway } & $0.0058 * * *$ & 0.0015 & $0.0043 * * *$ & 0.0005 & $0.2900 * * *$ \\
\hline & $(0.0010)$ & $(0.0010)$ & $(0.0010)$ & $(0.0011)$ & $(0.0241)$ \\
\hline Year-fixed effect & Yes & Yes & Yes & Yes & Yes \\
\hline Province-fixed & Yes & Yes & Yes & Yes & Yes \\
\hline \multicolumn{6}{|l|}{ effect } \\
\hline within $\mathrm{R}^{2}$ & 0.954 & 0.960 & 0.861 & 0.874 & 0.659 \\
\hline F- statistics & $291.74 * * *$ & $330.20 * * *$ & $87.80 * * *$ & $96.64 * * *$ & $28.15 * * *$ \\
\hline Robust Hausman & $75.24 * * *$ & $107.00 * * *$ & $26.98 * * *$ & $24.54 * * *$ & $39.87 * * *$ \\
\hline Greene test & $4628.94 * * *$ & $5885.09 * * *$ & $4257.58 * * *$ & $5438.18 * * *$ & $3982.19 * * *$ \\
\hline Wooldridge test & $40.91 * * *$ & $39.89 * * *$ & $36.69 * * *$ & $37.10 * * *$ & $2.84 *$ \\
\hline Pesaran test & $50.48 * * *$ & $50.19 * * *$ & $11.11 * * *$ & $10.00 * * *$ & $23.58 * * *$ \\
\hline
\end{tabular}




\begin{tabular}{|c|c|c|c|c|c|c|}
\hline \multicolumn{2}{|c|}{ Group } & 29 & 29 & \multicolumn{2}{|l|}{29} & 29 \\
\hline \multirow{2}{*}{\multicolumn{7}{|c|}{ Observations }} \\
\hline & & & & & & \\
\hline 911 & \multicolumn{6}{|l|}{ Table 11} \\
\hline 912 & \multicolumn{6}{|c|}{ SMEPRs and carbon emissions: test results based on the intermediary effect of industrial structure } \\
\hline & & c & $\mathbf{c}^{\prime}$ & $\mathbf{a}$ & $\mathbf{b}$ & $\mathbf{a b}$ \\
\hline & \multirow[t]{2}{*}{ LNCE } & $2.6984 * * *$ & $2.1824 * * *$ & $34.6524 * * *$ & $0.0149 * * *$ & 0.516 \\
\hline & & $(0.2081)$ & $(0.2004)$ & $(4.9750)$ & $(0.0014)$ & \\
\hline & \multirow[t]{2}{*}{$L N C E I$} & $2.8220 * * *$ & $2.3696^{* * *}$ & $34.6524 * * *$ & $0.0131 * * *$ & 0.454 \\
\hline & & $(0.2113)$ & $(0.2071)$ & $(4.9750)$ & $(0.0014)$ & \\
\hline & \multicolumn{6}{|c|}{ Bootstrap test } \\
\hline & & & \multicolumn{2}{|c|}{$95 \%$ Conf. Interval } & \multirow[t]{2}{*}{ Test result } & \multirow[t]{2}{*}{ Conclusion } \\
\hline & & & LLCI & ULCI & & \\
\hline & \multirow[t]{2}{*}{$L N C E$} & Indirect effect & 0.3051 & 0.8093 & \multirow[t]{2}{*}{ Reject H0 } & \multirow[t]{2}{*}{ Partial mediation } \\
\hline & & Direct effect & 1.8120 & 2.5961 & & \\
\hline & \multirow[t]{2}{*}{ LNCEI } & Indirect effect & 0.2674 & 0.6909 & \multirow[t]{2}{*}{ Reject H0 } & \multirow[t]{2}{*}{ Partial mediation } \\
\hline & & Direct effect & 1.9833 & 2.8304 & & \\
\hline
\end{tabular}

\section{Table 12}

Robustness test 1

\begin{tabular}{|c|c|c|c|c|c|c|c|}
\hline \multirow{2}{*}{$\begin{array}{l}\text { Explanatory } \\
\text { variables }\end{array}$} & \multicolumn{2}{|l|}{ TFP } & \multicolumn{2}{|l|}{$L N C E$} & \multicolumn{2}{|l|}{ LNCEI } & \multirow{2}{*}{$\begin{array}{l}I S \\
(7)\end{array}$} \\
\hline & (1) & (2) & (3) & (4) & (5) & (6) & \\
\hline \multirow[t]{3}{*}{$M 1$} & $0.017 *$ & $0.017 *$ & $-0.150 * *$ & $-0.147 * *$ & $-0.149 * *$ & $-0.146 * *$ & -0.156 \\
\hline & $(0.0095)$ & $(0.0095)$ & $*$ & $*$ & $*$ & $*$ & $(0.8694)$ \\
\hline & & & $(0.0388)$ & $(0.0356)$ & $(0.0399)$ & $(0.0372)$ & \\
\hline \multirow[t]{2}{*}{$M 2$} & 0.011 & 0.005 & $0.205 * * *$ & $0.101 * *$ & $0.147 * * *$ & 0.050 & $5.914 * * *$ \\
\hline & $(0.0107)$ & $(0.0109)$ & $(0.0435)$ & $(0.0409)$ & $(0.0448)$ & $(0.0428)$ & $(0.9760)$ \\
\hline \multirow[t]{2}{*}{$I S$} & & $0.001 * *$ & & $0.018 * * *$ & & $0.016 * * *$ & \\
\hline & & $(0.0004)$ & & $(0.0014)$ & & $(0.0015)$ & \\
\hline \multirow[t]{3}{*}{ Control_Urban } & $-0.001 * *$ & $-0.001 * *$ & -0.002 & -0.001 & $-0.004 * *$ & $-0.004 * *$ & -0.022 \\
\hline & $*$ & $*$ & $(0.0012)$ & $(0.0011)$ & $*$ & $*$ & $(0.0266)$ \\
\hline & $(0.0003)$ & $(0.0003)$ & & & $(0.0012)$ & $(0.0011)$ & \\
\hline \multirow[t]{2}{*}{ Control_RD } & -0.003 & -0.005 & $0.044 *$ & 0.006 & $0.112 * * *$ & $0.076^{* * *}$ & $2.174 * * *$ \\
\hline & $(0.0055)$ & $(0.0056)$ & $(0.0224)$ & $(0.0209)$ & $(0.0231)$ & $(0.0218)$ & $(0.5035)$ \\
\hline \multirow[t]{2}{*}{ Control_Open } & -0.009 & -0.010 & $-0.227 * *$ & $-0.247 * *$ & $-0.239 * *$ & $-0.257 * *$ & 1.091 \\
\hline & $(0.0082)$ & $(0.0082)$ & $*$ & $*$ & $*$ & $*$ & $(0.7490)$ \\
\hline
\end{tabular}




\begin{tabular}{llllllll} 
Control_Highway & $0.001^{*}$ & 0.000 & $0.007^{* * *}$ & $0.002^{*}$ & $0.006^{* * *}$ & 0.001 & $0.303^{* * *}$ \\
& $(0.0003)$ & $(0.0003)$ & $(0.0011)$ & $(0.0011)$ & $(0.0011)$ & $(0.0011)$ & $(0.0241)$ \\
Year-fixed effect & Yes & Yes & Yes & Yes & Yes & Yes & Yes \\
Province-fixed & Yes & Yes & Yes & Yes & Yes & Yes & Yes \\
effect & & & & & & & \\
within R & 0.377 & 0.382 & 0.947 & 0.955 & 0.835 & 0.8564 & 0.655 \\
F-statistics & $9.36^{* * *}$ & $9.37 * * *$ & $247.56^{* *}$ & $290.49^{* *}$ & $71.07 * * *$ & $82.01 * * *$ & $27.14 * * *$ \\
& & & $*$ & $*$ & & & \\
Group & 29 & 29 & 29 & 29 & 29 & 29 & 29 \\
Observations & 870 & 870 & 870 & 870 & 870 & 870 & 870 \\
\hline
\end{tabular}

916

Table 13
Robustness test 2: stepwise regression results

\begin{tabular}{|c|c|c|c|c|c|c|c|}
\hline \multirow{2}{*}{$\begin{array}{l}\text { Explanatory } \\
\text { variables }\end{array}$} & \multicolumn{2}{|l|}{ TFP } & \multicolumn{2}{|l|}{$L N C E$} & \multicolumn{2}{|l|}{ LNCEI } & \multirow{2}{*}{$\begin{array}{l}I S \boldsymbol{S} 2 \\
(7)\end{array}$} \\
\hline & (1) & (2) & (3) & (4) & (5) & (6) & \\
\hline \multirow[t]{2}{*}{$E M$} & -0.043 & -0.071 & $2.698 * * *$ & $2.271 * * *$ & $2.822 * * *$ & $2.462 * * *$ & $25.970 * * *$ \\
\hline & $(0.0551)$ & $(0.0564)$ & $(0.2081)$ & $(0.2027)$ & $(0.2113)$ & $(0.2093)$ & $(3.9935)$ \\
\hline \multirow[t]{2}{*}{$I S 2$} & & $0.001 * *$ & & $0.016^{* * *}$ & & $0.014 * * *$ & \\
\hline & & $(0.0005)$ & & $(0.0017)$ & & $(0.0018)$ & \\
\hline \multirow[t]{2}{*}{ Control_Urban } & $-0.001 * * *$ & $-0.001 * * *$ & $-0.004 * * *$ & $-0.002 *$ & $-0.006 * * *$ & $-0.004 * * *$ & $-0.103 * * *$ \\
\hline & $(0.0003)$ & $(0.0003)$ & $(0.0011)$ & $(0.0010)$ & $(0.0011)$ & $(0.0011)$ & $(0.0206)$ \\
\hline \multirow[t]{2}{*}{ Control_RD } & -0.004 & -0.005 & 0.010 & -0.014 & $0.074 * * *$ & $0.054 * * *$ & $1.438 * * *$ \\
\hline & $(0.0056)$ & $(0.0056)$ & $(0.0210)$ & $(0.0201)$ & $(0.0213)$ & $(0.0208)$ & $(0.4033)$ \\
\hline \multirow[t]{2}{*}{ Control_Open } & -0.010 & -0.010 & $-0.186^{* * *}$ & $-0.193^{* * *}$ & $-0.188 * * *$ & $-0.194 * * *$ & 0.455 \\
\hline & $(0.0083)$ & $(0.0082)$ & $(0.0312)$ & $(0.0297)$ & $(0.0317)$ & $(0.0306)$ & $(0.5993)$ \\
\hline \multirow[t]{2}{*}{ Control_Highway } & $0.001 * *$ & 0.000 & $0.006^{* * *}$ & $0.003 * * *$ & $0.004 * * *$ & $0.002 *$ & $0.187 * * *$ \\
\hline & $(0.0003)$ & $(0.0003)$ & $(0.0010)$ & $(0.0010)$ & $(0.0010)$ & $(0.0010)$ & $(0.0193)$ \\
\hline Year-fixed effect & Yes & Yes & Yes & Yes & Yes & Yes & Yes \\
\hline Province-fixed & Yes & Yes & Yes & Yes & Yes & Yes & Yes \\
\hline \multicolumn{8}{|l|}{ effect } \\
\hline within $\mathrm{R}^{2}$ & 0.375 & 0.378 & 0.954 & 0.958 & 0.861 & 0.870 & 0.763 \\
\hline F-statistics & $9.43^{* * *}$ & $9.50 * * *$ & $291.74 * * *$ & $319.92 * * *$ & $87.80^{* * *}$ & $93.60 * * *$ & $46.13 * * *$ \\
\hline Group & 29 & 29 & 29 & 29 & 29 & 29 & 29 \\
\hline Observations & 870 & 870 & 870 & 870 & 870 & 870 & 870 \\
\hline
\end{tabular}


Table 14

Robustness test 2: mediation effect test results

\begin{tabular}{|c|c|c|c|c|c|}
\hline & c & c' & $\mathbf{a}$ & $\mathbf{b}$ & $\mathbf{a b}$ \\
\hline \multirow[t]{2}{*}{$T F P$} & -0.043 & -0.071 & $25.970 * * *$ & $0.001 * *$ & 0.029 \\
\hline & $(0.0551)$ & $(0.0564)$ & $(3.9935)$ & $(0.0005)$ & \\
\hline \multirow[t]{2}{*}{$L N C E$} & $2.698 * * *$ & $2.271 * * *$ & $25.970 * * *$ & $0.016 * * *$ & 0.428 \\
\hline & $(0.2081)$ & $(0.2027)$ & $(3.9935)$ & $(0.0017)$ & \\
\hline \multirow[t]{2}{*}{ LNCEI } & $2.822 * * *$ & $2.462 * * *$ & $25.970 * * *$ & $0.014 * * *$ & 0.361 \\
\hline & $(0.2113)$ & $(0.2093)$ & $(3.9935)$ & $(0.0018)$ & \\
\hline \multicolumn{6}{|c|}{ Bootstraptest } \\
\hline & & \multicolumn{2}{|c|}{$95 \%$ Conf. Interval } & Test result & Conclusion \\
\hline & & LLCI & ULCI & & \\
\hline \multirow[t]{2}{*}{$T F P$} & Indirect effect & 0.0034 & 0.0542 & Reject H0 & Full mediation \\
\hline & Direct effect & -0.1769 & 0.0377 & & \\
\hline \multirow[t]{2}{*}{$L N C E$} & Indirect effect & 0.2806 & 0.6213 & Reject H0 & Partial mediation \\
\hline & Direct effect & 1.9265 & 2.7381 & & $(0.1885)$ \\
\hline \multirow[t]{2}{*}{ LNCEI } & Indirect effect & 0.2139 & 0.5305 & Reject H0 & Partial mediation \\
\hline & Direct effect & 2.0656 & 2.9132 & & $(0.1466)$ \\
\hline
\end{tabular}

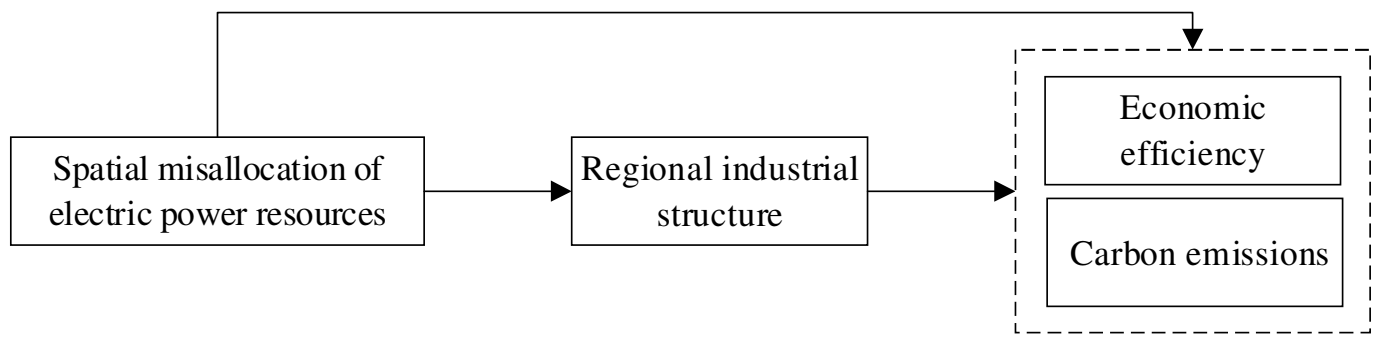




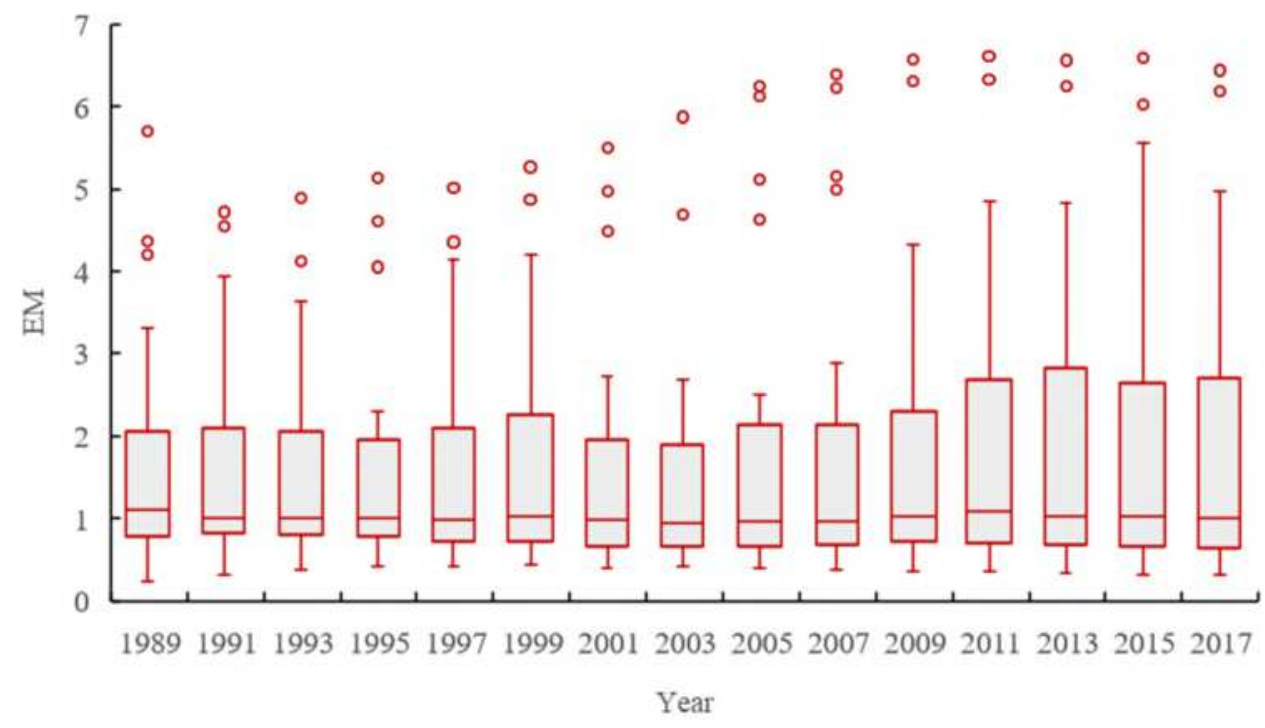

Fig. 2 Comparison of the level of spatial misallocation of power resources from 1988-2017

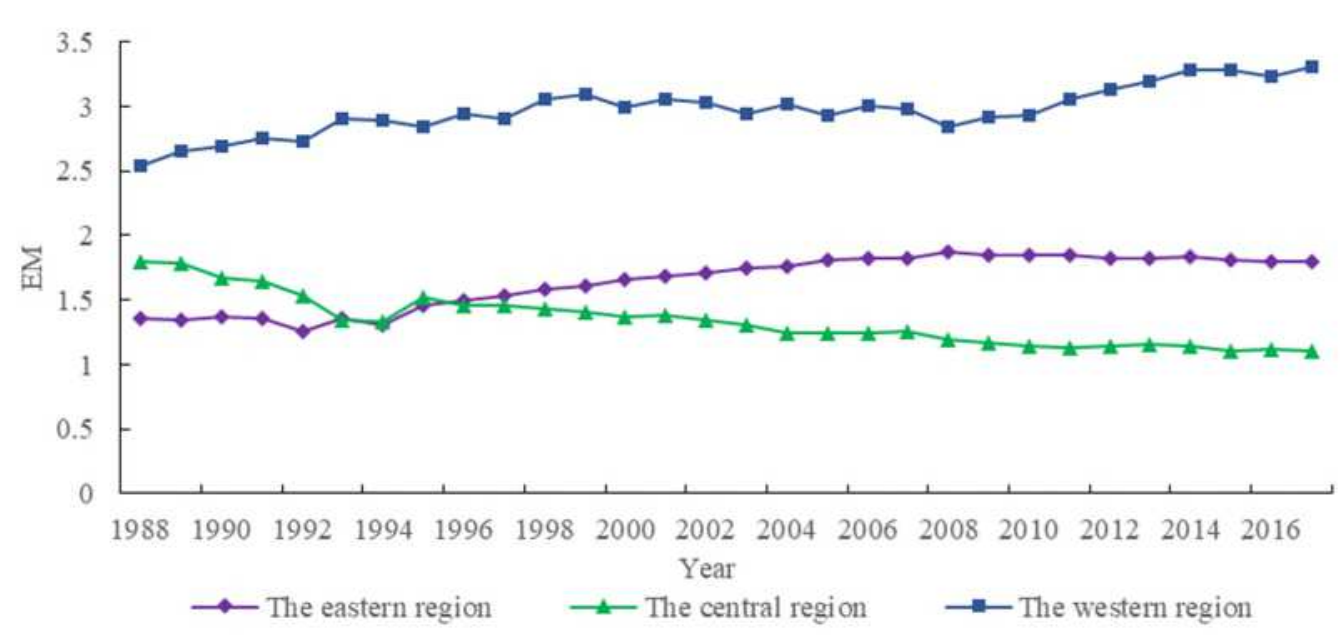

Fig. 3 The evolution of trends in the spatial misallocation of power resources at the regional level

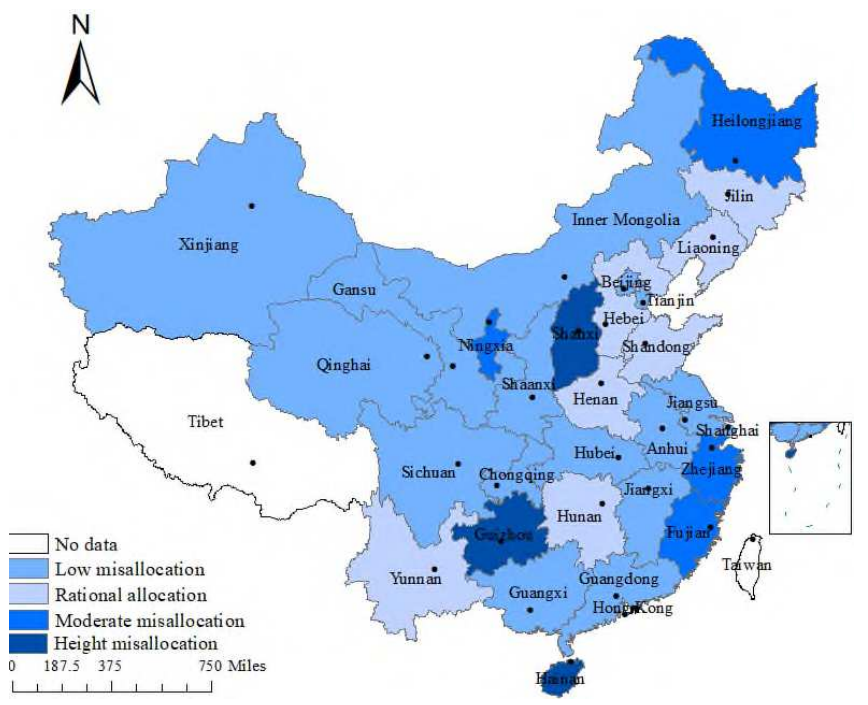

36 


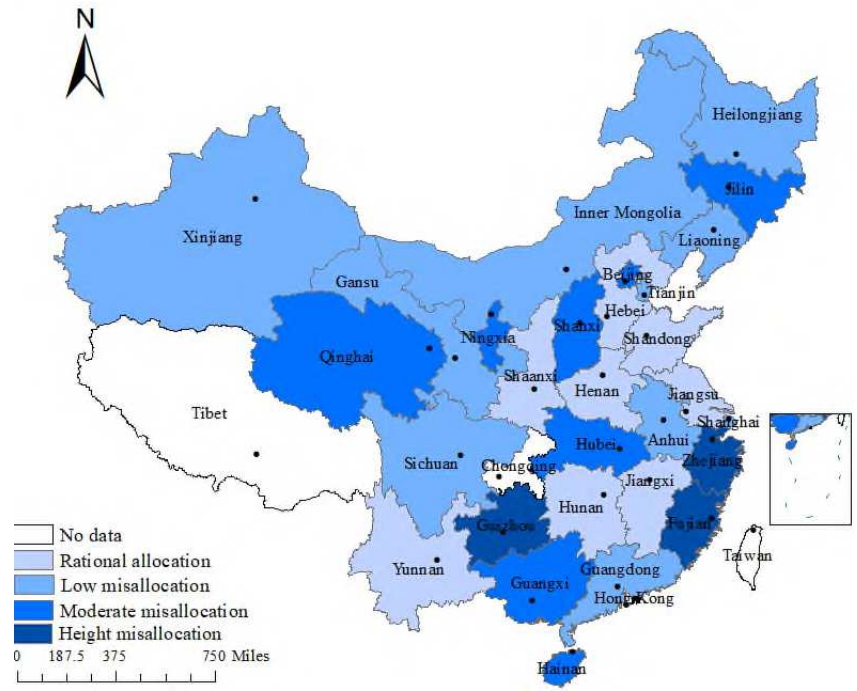

(b) 2003 and or [2,5) as moderate misallocation. Set EM in the interval [0.5,0.8) and or [1.2,2) as low misallocation. Set EM in the interval $[0.8,1.2)$ as rational allocation. 


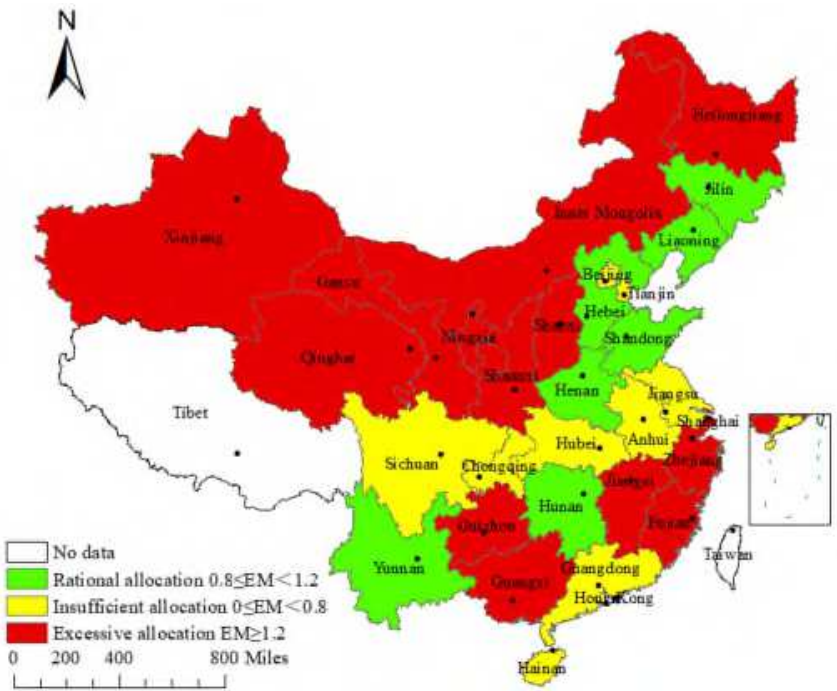

(a) 1988

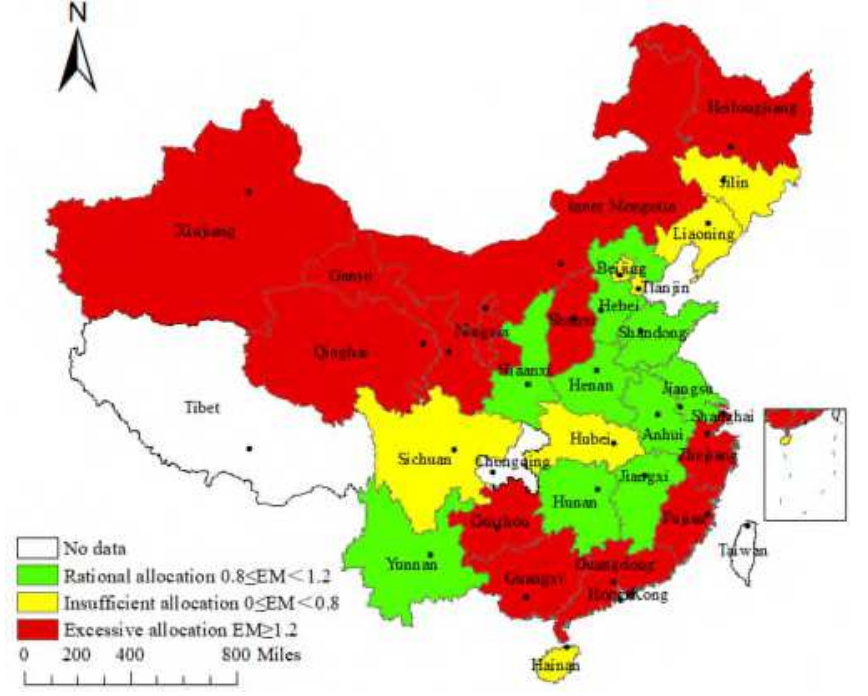

(b) 2003

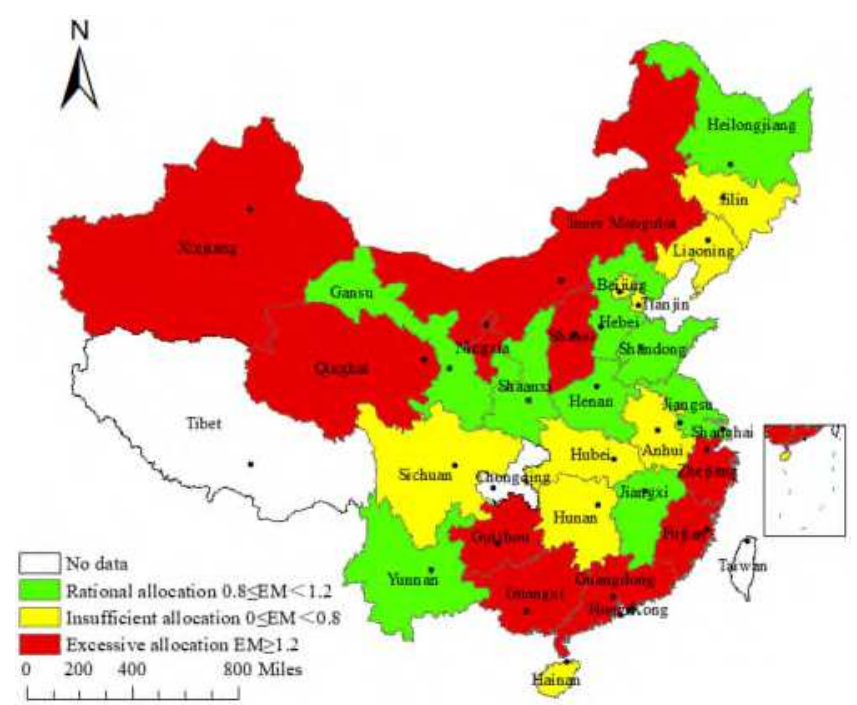

(c) 2017

Fig. 5 The evolution trends in the direction of spatial misallocation of power resources at the provincial level 


\section{Supplementary Files}

This is a list of supplementary files associated with this preprint. Click to download.

- Appendix.docx

- Code.docx

- Data.xlsx 